\title{
LA CERÁMICA DE IMPORTACIÓN DE LOS CONTEXTOS DE ÉPOCA CLAUDIA DEL FORUM DE AEMINIUM (COIMBRA, PORTUGAL)
}

\author{
THE IMPORTED POTTERY FROM THE EARLY EMPIRE CONTEXTS \\ OF AEMINIUM FORUM (COIMBRA, PORTUGAL)
}

\author{
RICARDO COSTEIRA DA SILVA \\ Faculdade de Letras da Universidade de Coimbra (Portugal). Centro de Estudos em Arqueologia, \\ Artes e Ciências do Património (CEAACP). Palácio SubRipas, 3000-395 Coimbra, Portugal. \\ Correo-e: ricardo_silva78@hotmail.com. ORCID: https://orcid.org/0000-0003-1006-8562 \\ PEDRO C. CARVALHO \\ Faculdade de Letras da Universidade de Coimbra (Portugal). Centro de Estudos em Arqueologia, \\ Artes e Ciências do Património (CEAACP). Palácio SubRipas, 3000-395 Coimbra, Portugal. \\ Correo-e: pedrooak@gmail.com. ORCID: https://orcid.org/0000-0003-3749-3542 \\ ADOLFO FERNÁNDEZ FERNÁNDEZ \\ Marie Curie Talent Research. Campus do Mar da Universidade de Vigo (España). \\ Grupo de Estudos de Arqueoloxía, Antigüidade e Territorio (GEAAT). Investigador del Centro de Estudos Clássicos e Humanísticos \\ da Universidade de Coimbra (CECH). Facultade de Historia da UVigo. Campus As Lagoas, 32004, Ourense. \\ Correo-e: adolfo@uvigo.es. ORCID: https://orcid.org/0000-0003-2981-6604
}

\begin{abstract}
Resumen: Las intervenciones arqueológicas realizadas de forma más o menos continuada desde la década de los 90 del siglo XX en el espacio del antiguo foro y criptopórtico de $\mathrm{Ae}$ minium (Coímbra) permitieron exhumar una importante colección de material cerámico de época romana. Los conjuntos cerámicos más relevantes provienen de contextos sellados y asociados a los niveles de relleno coetáneos a la construcción del forum, a mediados del siglo I d.C.

En este trabajo se presenta el importante conjunto de cerámica importada recuperada en los niveles altoimperiales que, articulados con otros indicadores cronológicos, han sustentado una cronología rigurosa para la edificación del complejo forense en época del emperador Claudio, sucediendo a un edificio inicial de época augustea.
\end{abstract}

Palabras clave: Cerámica romana importada; Forum de $\mathrm{Ae}$ minium; mediados del siglo I d.C.; terra sigillata; contexto estratigráfico.

\begin{abstract}
Archaeological campaigns carried out at the forum and cryptoporticus of Aeminium, more or less continuously since the 1990s, have allowed the gathering of a significant collection of Roman pottery. The most important ceramic set comes from the construction levels associated to the enlargement of the forum, in the middle of the 1st century AD.

This text presents the collection of imported pottery gathered in these stratigraphic contexts. Their study, together with other chronological indicators, has enabled the second stage of construction of the forum of Aeminium to be dated to the time of Claudius, succeeding an Augustan initial phase.
\end{abstract}

Keywords Roman imported pottery; Forum of Aeminium; mid 1st century AD; Terra sigillata; stratigraphic context. 


\section{INTRODUCCIÓN}

Sucediendo a un poblado protohistórico (Almeida et al. 2015) y con una localización geoestratégica notable (próxima al Oceano, en las márgenes de un río navegable y en el trayecto de una vía que comunicaba Olisipo con Bracara Augusta), el oppidum de Aeminium se convierte en capital de ciuitas en época de Augusto (Alarcão 2008). La primera gran renovación urbana de la ciudad datará precisamente de ese momento, en torno al cambio de Era (Mantas 1992). Excavaciones recientes revelaron también la presencia de un forum de época de Augusto (Alarcão et al. 2009). Décadas después, en tiempos del emperador Claudio, ese primer forum fue completamente reformulado, dando lugar a otro más consecuente con la importancia de la ciudad (Carvalho 1998). Del forum de Claudio se conserva esencialmente el criptopórtico, sobre el cual se asentó el edificio. Formado por dos pisos de galerías abovedadas, este criptopórtico fue concebido como plataforma de soporte del forum y construido para vencer la acentuada pendiente en esa zona central de la ciudad (Oleiro y Alarcão 1973). El forum contaba con una arquitectura original, con pórticos de dos pisos y un plan diseñado en función de una basílica absidiada (basilica cum aede vitruviana) que funcionaba como capilla del culto imperial (aedes Augusti) (Carvalho 1998; Alarcão et al. 2009) (figs. 1 y 2).

El extenso programa de intervenciones arqueológicas (desarrolladas entre 1992 y 2008) que antecedieron y acompañaron el proceso de remodelación y ampliación del Museo Nacional de Machado de Castro en Coímbra (Carvalho 2013) permitió recuperar un conjunto de datos, también desde el punto de vista del conjunto artefactual exhumado, que vinieron a definir las sucesivas etapas de ocupación de este espacio. La secuencia estratigráfica estudiada aparece marcada por la presencia de niveles de construcción del edificio del foro de Claudio y la ausencia de vestigios que documenten su fase de uso propiamente dicha. Por el contrario, los niveles de destrucción, a pesar de ser escasos, permitieron por primera vez aislar y estudiar algunos conjuntos cerámicos provenientes de contextos más tardíos asociados al abandono y post-abandono del foro (Silva et al. 2015).

De este modo, la colección cerámica que presentamos en este trabajo se centra en los contextos altoimperiales (siglo I d.C.) recuperada en los niveles de relleno relacionados con la construcción del criptopórtico de Aeminium. En este caso, destaca la identificación, por primera vez, de niveles estratigráficos fechados a inicios del siglo I, coetáneos a la primera fase de construcción del forum, fechada en época de Augusto. Sin embargo, los conjuntos más significativos continúan siendo aquellos recuperados en los niveles de relleno asociados a la ampliación y profunda remodelación del foro y criptopórtico a mediados del siglo I, probablemente durante el reinado de Claudio. Son aquellos materiales que fueron recuperados en secuencias estratigráficas contextualizadas y selladas, correspondiéndose con voluminosos rellenos depositados en el momento de la construcción de las paredes del criptopórtico, paredes que sirvieron también de cimentación y base de los edificios del forum (fig. 3).

Excavaciones recientes revelaron también otros restos de la trama urbana en los alrededores del foro, donde destacan partes de cloacas, que indican la presencia de calles, además de partes de algunos edificios privados, incluyendo una posible fullonica (Silva 2011). Estas campañas arqueológicas permitieron proyectar la imagen de la fachada más monumental del complejo forense y averiguar el modo en que la composición de la trama urbana se encontraría diseñada en aquella zona de la ciudad romana (Alarcão et al. 2009). La renovación urbanística del barrio occidental habría sido motivada por la ampliación de uno de los principales ejes viarios de la ciudad, el decumanus maximus. Los resultados de las intervenciones realizadas en esta área fueron ya publicados, quedando por presentar el estudio de la cerámica recuperada en los referidos contextos altoimperiales, carencia que ahora aquí se corrige.

Por todo ello, el objetivo de este artículo es el de presentar por primera vez el vasto conjunto de materiales provenientes de los niveles asociados a la construcción del nuevo edificio forense, que substituye un foro previo de época de Augusto. El preciso estudio cronotipológico, prestando especial atención a los materiales datantes (vajilla fina, ánforas, paredes finas, etc.), unido a los datos de la contabilización muestran la base científica en la que se asienta la evolución constructiva -anteriormente publicada- del espacio forense de $A e$ minium y que solamente fue esbozada en base a unos pocos materiales datantes (Carvalho 1998). La publicación de este importante conjunto permite además un análisis crítico de la colección y con ello, la crítica y reflexión de la propia evolución urbana de este sector de la ciudad. Además, los numerosos e importantes materiales importados muestran una realidad económicocomercial de una ciudad romana de la fachada atlántica (nivel micro), de la Lusitania (nivel macro) en un momento tan concreto como el reinado del emperador Claudio. 


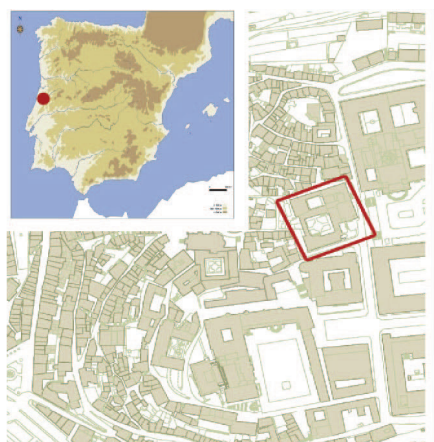

a
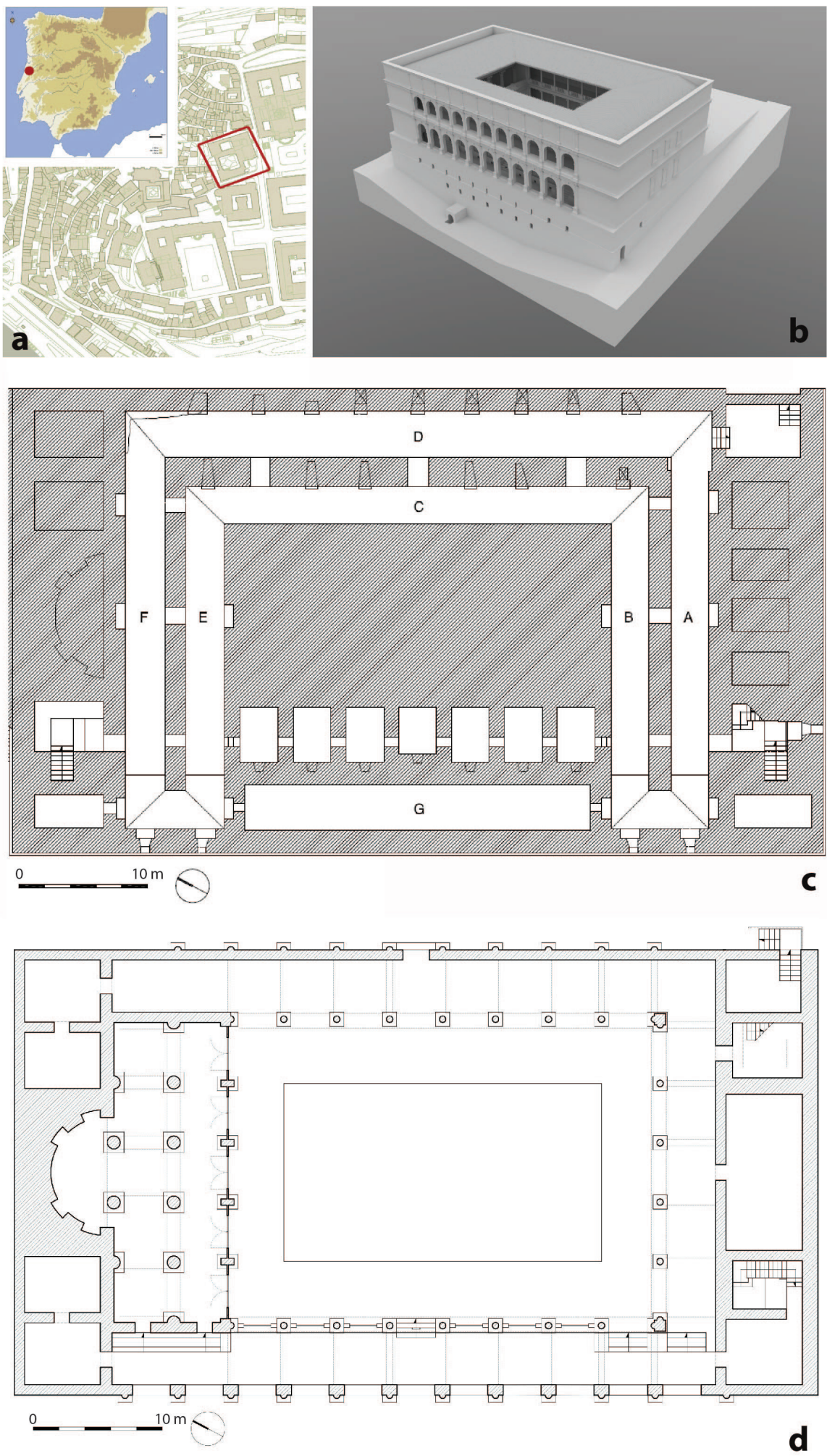

Figura 1. Museo Nacional de Machado de Castro / Forum de Aeminium en Coímbra (a); Reconstitución 3D del forum de Claudio de Aeminium (b); Planta del piso superior del criptopórtico (c); Planta (parcial) del forum de época Claudia de Aeminium (d). 
Teniendo en cuenta el conjunto de problemáticas que el estudio de esta colección podría ayudar a resolver, optamos por individualizar los conjuntos analizados según su zona de proveniencia, diferenciándose los contextos identificados en el área del complejo forense (fig. 1-3), de los recuperados en el área del sector urbano occidental, ya en el exterior del foro (figs. 4 y 5).

Por último, señalar la poca presencia de materiales importados en los contextos más antiguos, asociados a la construcción del foro primitivo (en época de Augusto). En estos niveles se recuperó un pequeño fragmento de TS itálica y fragmentos de borde, asa y pivote de un ánfora, que por sus características deberían pertenecer a un contenedor Dressel 1A de procedencia itálica. Se hace necesario destacar que en este caso, la obtención de dataciones se apoyó de forma determinante en la propia secuencia estratigráfica, siendo importante también la ausencia de elementos o producciones como indicador cronológico.

\section{LAS IMPORTACIONES CERÁMICAS DE LOS CONTEXTOS ALTOIMPERIALES (MEDIADOS DEL S. I D.C.) DEL COMPLEJO FORENSE.}

\subsection{Cerámica "campaniense"}

En este tipo de contextos de rellenos intencionados es frecuente encontrarse un conjunto de materiales considerados residuales (con una cronología de producción claramente anterior) cuya presencia se debe a revueltos y a tierras transportadas de otras zonas. Este parece ser el caso de tres fragmentos recuperados de cerámica de barniz negro del tipo campaniense. A pesar de que solo dos permiten clasificación, todos son imitaciones de la clase B, integrables en el tipo F, con barniz gris brillante metalizado, ligeramente espeso y parcialmente craquelado en el exterior. La pasta es ocre amarillenta, compacta y de fractura regular.

Uno de los borde recuperados (fig. 6, 1), de paredes exvasadas, puede pertenecer a una copa de la forma Lamboglia 2 (F 1230) correspondiente a una variante morfológica producida en varias oficinas del Mediterráneo occidental, especialmente entre los siglos II y I a.C. (Morel 1981: 94-96). Esta forma presenta una amplia variedad de perfiles, lo que hace difícil determinar su centro de origen (Bonet Rosado y Mata Parreño 1988: 22), pudiendo haber sufrido en algunos casos un aumento gradual del borde y una mayor abertura de las paredes. En este caso, las características de la pieza sugieren una cronología tardía, posiblemente ya de finales del siglo I a.C. (Delgado 1971: 413).

La otra pieza se corresponde al tipo Lamboglia 5 (F 2250). Este tipo de páteras es, de lejos, la forma más común en la fachada atlántica de la Península (Luís 2010: 119). El plato figurado, de fondo plano y paredes oblicuas es una forma tardía, normalmente asociada a contextos de mediados del s. I a.C. (fig. 6, 2).

\subsection{Terra sigillata}

En estos contextos se recuperaron más de novecientos fragmentos (933) de terra sigillata, exclusivamente itálica y sudgálica. Aunque se verifica una ligera supremacía de la TS de tipo itálico (56,6\%-528 fragmentos), las producciones del sur de la Galia (43,4\%-405 fragmentos) adquieren una mayor importancia en estos niveles estratigráficos, en la medida que estas, asociadas a otros materiales, se convierten en el elemento primordial para la datación de los mismos. No obstante, en ambas producciones no fueron muchos los fragmentos clasificados tipológicamente, apenas un 23,3\% (123 frag.) de las producciones itálicas y un 29,4\% (119 frag.) de las sudgálicas.

\subsubsection{Terra sigillata itálica}

Dentro de la TSI predominan las formas lisas, algunas con decoración aplicada, que se distribuyen en un repertorio formal variado aunque no muy amplio. La excepción es un fragmento de borde de un cáliz, que constituye la única pieza decorada itálica y que fue recuperado en el contexto del barrio occidental ( $v$. infra). Remárquese la supremacía (algo habitual) de los platos (68 frag.) frente a las copas (55 frag.). Los platos aparecen representados por las formas Consp. 1 (4 frag.), Consp. 4 (10 frag.), Consp. 12 (5 frag.), Consp. 18 (17 frag.) y Consp. 20 (32 frag.). Entre las copas destacan las formas Consp. 22 (18 frag.), Consp. 23 (16 frag.), Consp. 32 (11 frag.) y Consp. 15 (3 frag.), identificándose también dos ejemplares de las formas Consp. 31 y Consp. 35, y un ejemplar de las formas Consp. 24; Consp. 33 y Consp. 34 (fig. 7).

Si tomamos como base las fases determinadas por C. Goudineau (1968: 376-377), comprobamos que las formas precoces se encuentran poco representadas en el conjunto. En este grupo destaca la presencia de una de las formas más antiguas, fechada entre el 40-15 a.C. (Ettlinger et al. 1990: 52), el plato Consp. 1 de paredes 

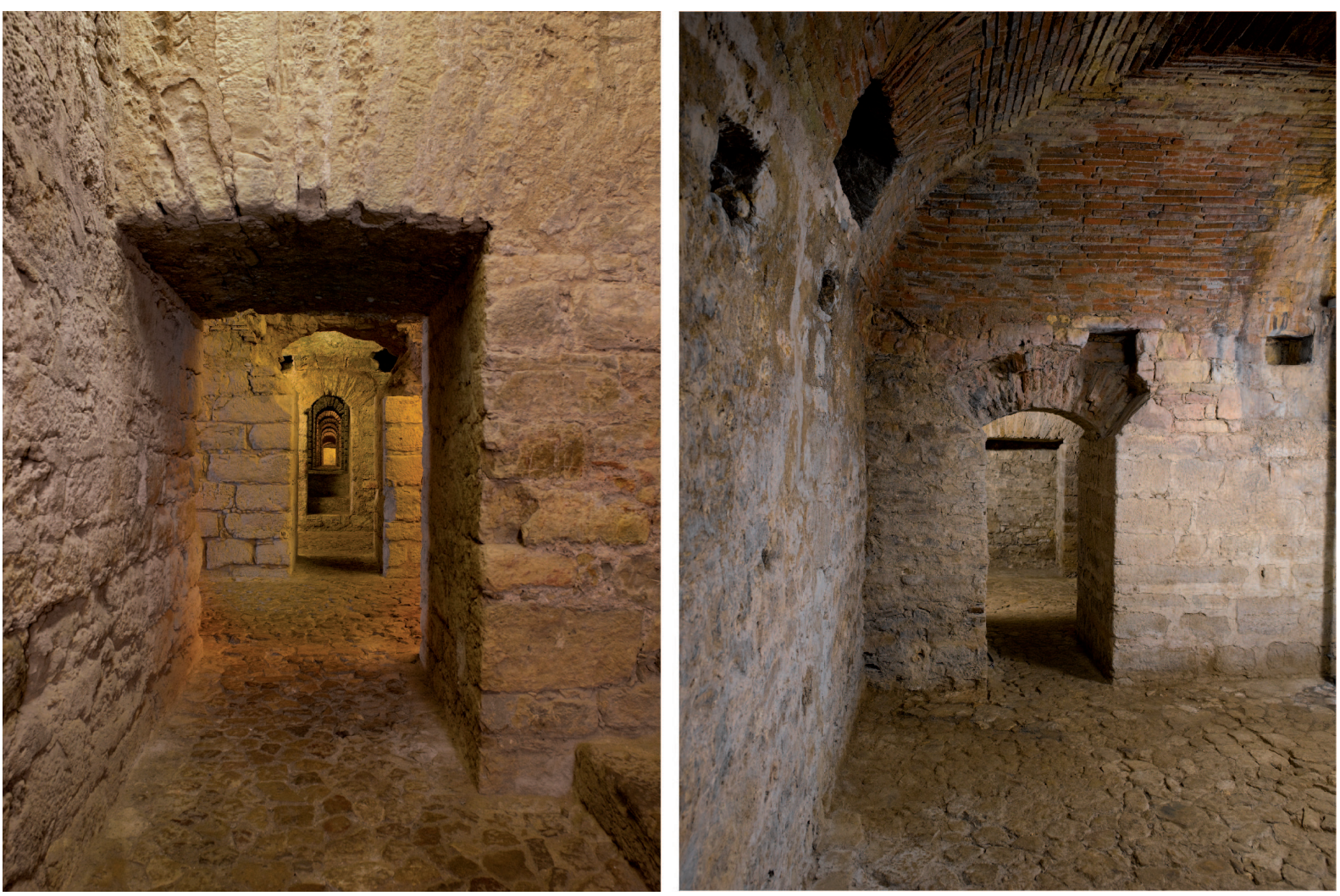

Figura 2. Imágenes del criptopórtico de Aeminium.

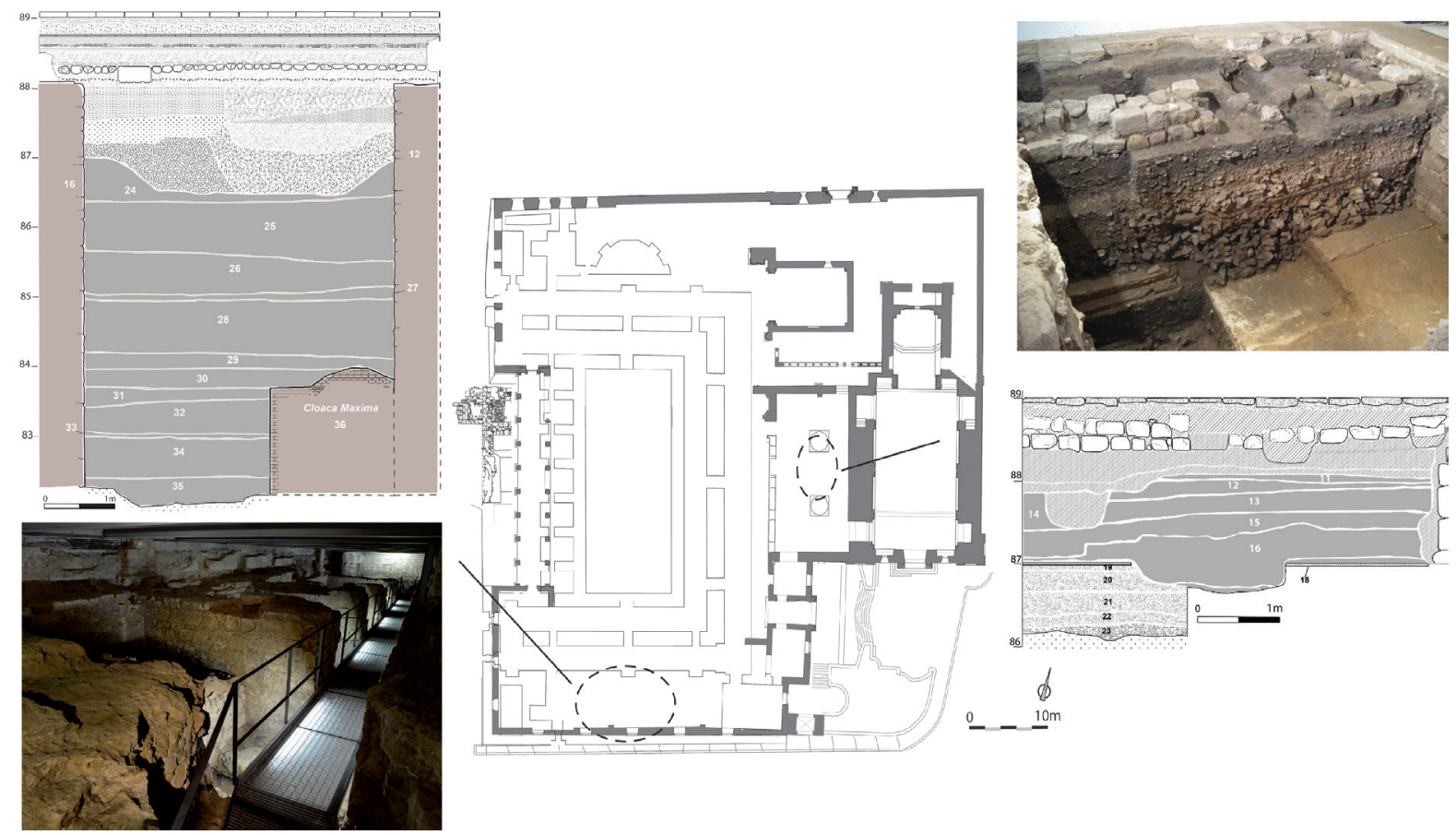

Figura 3. Detalles de secuencias estratigráficas asociadas a la construcción del criptopórtico/forum de Aeminium.

ISSN: 1133-4525 ISSN-e: 2255-3924 

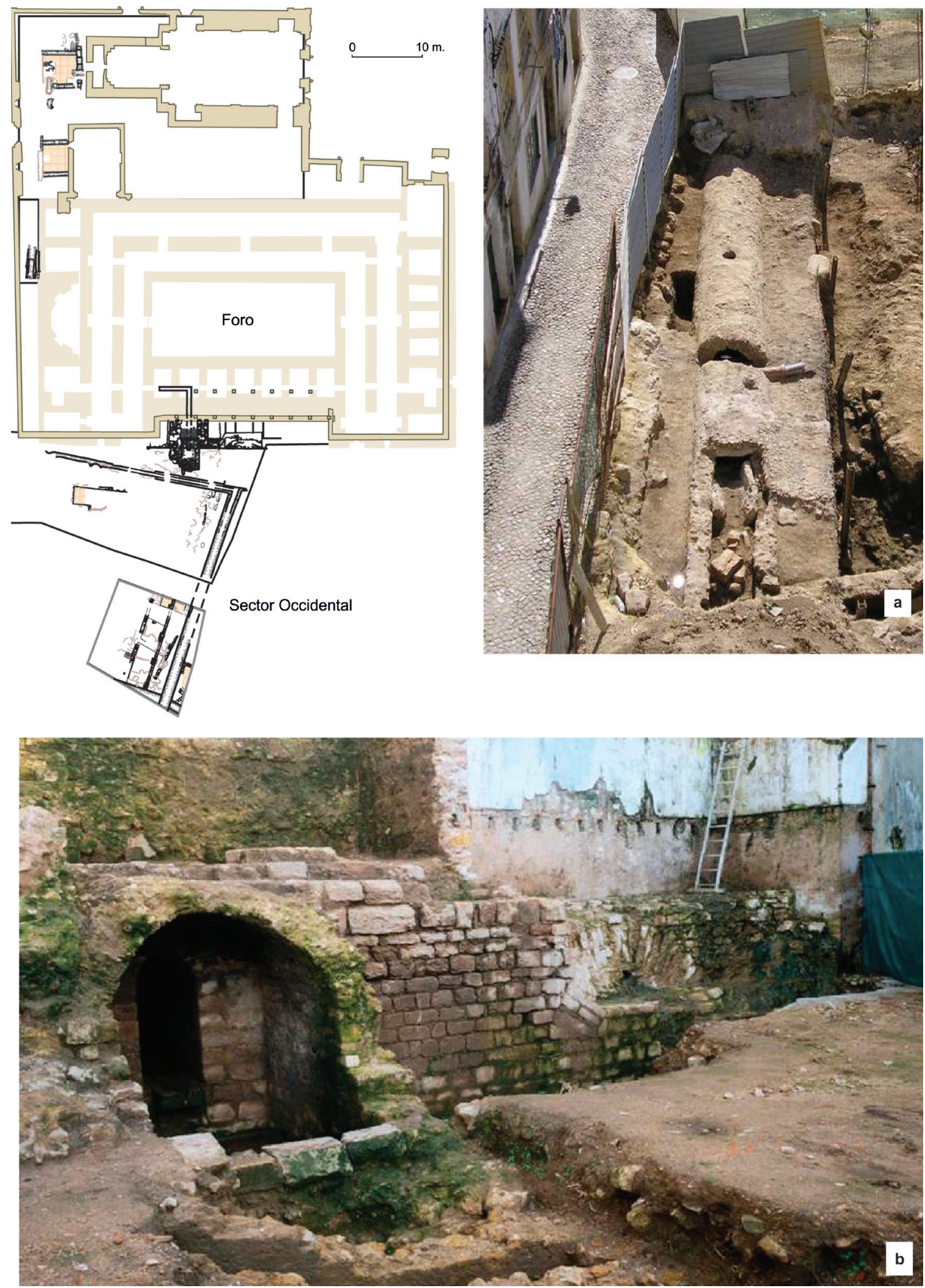

Figura 4. Sector urbano a poniente del forum: Cloaca Maxima (a) y fuente (b). 


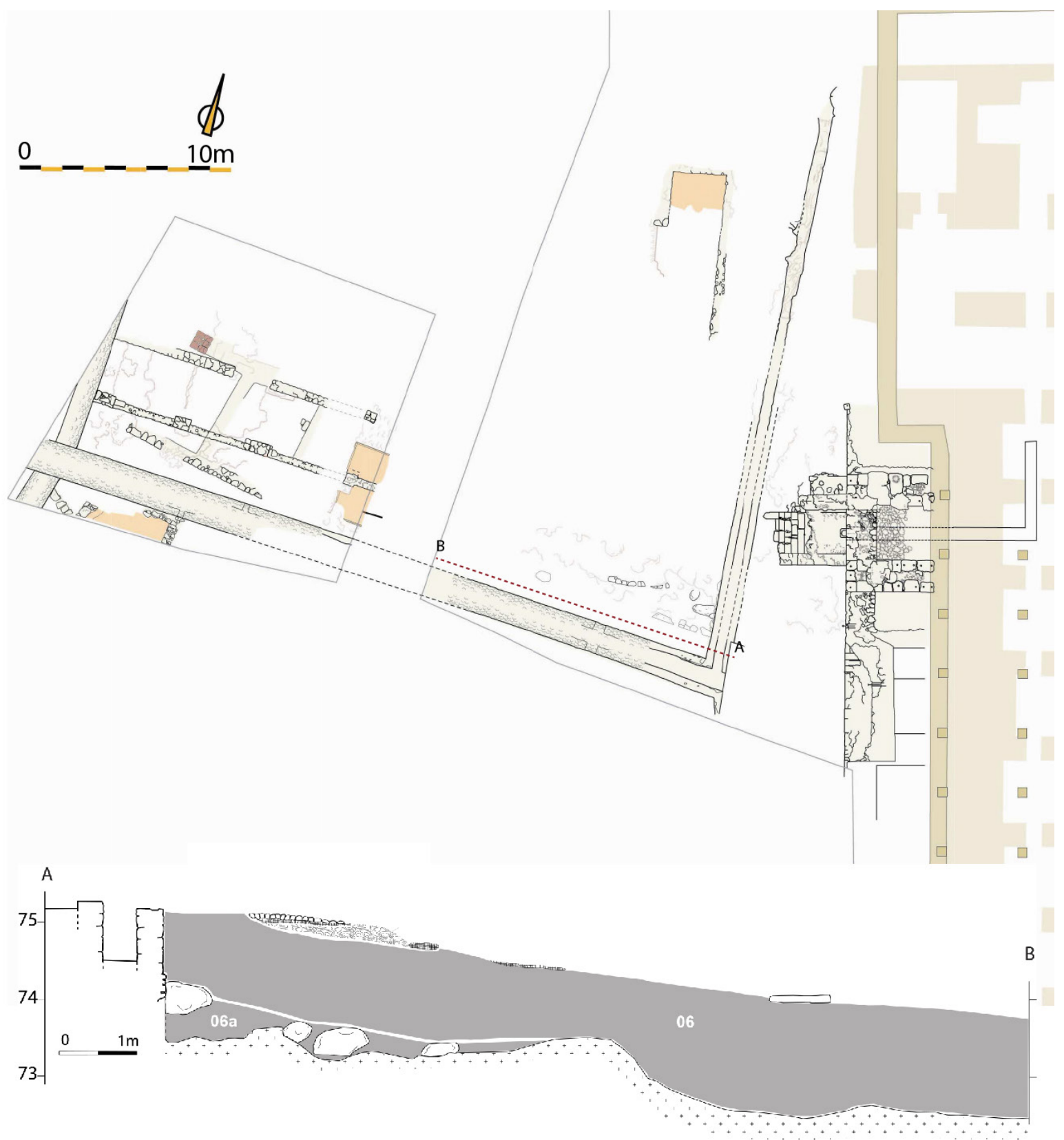

Figura 5. Secuencia estratigráfica asociada a la construcción de la Cloaca Maxima (sector occidental).

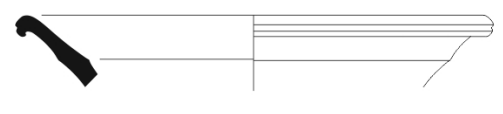

1

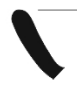

Figura 6. Cerámica "campaniense" de los contextos del complejo forense de Aeminium. 


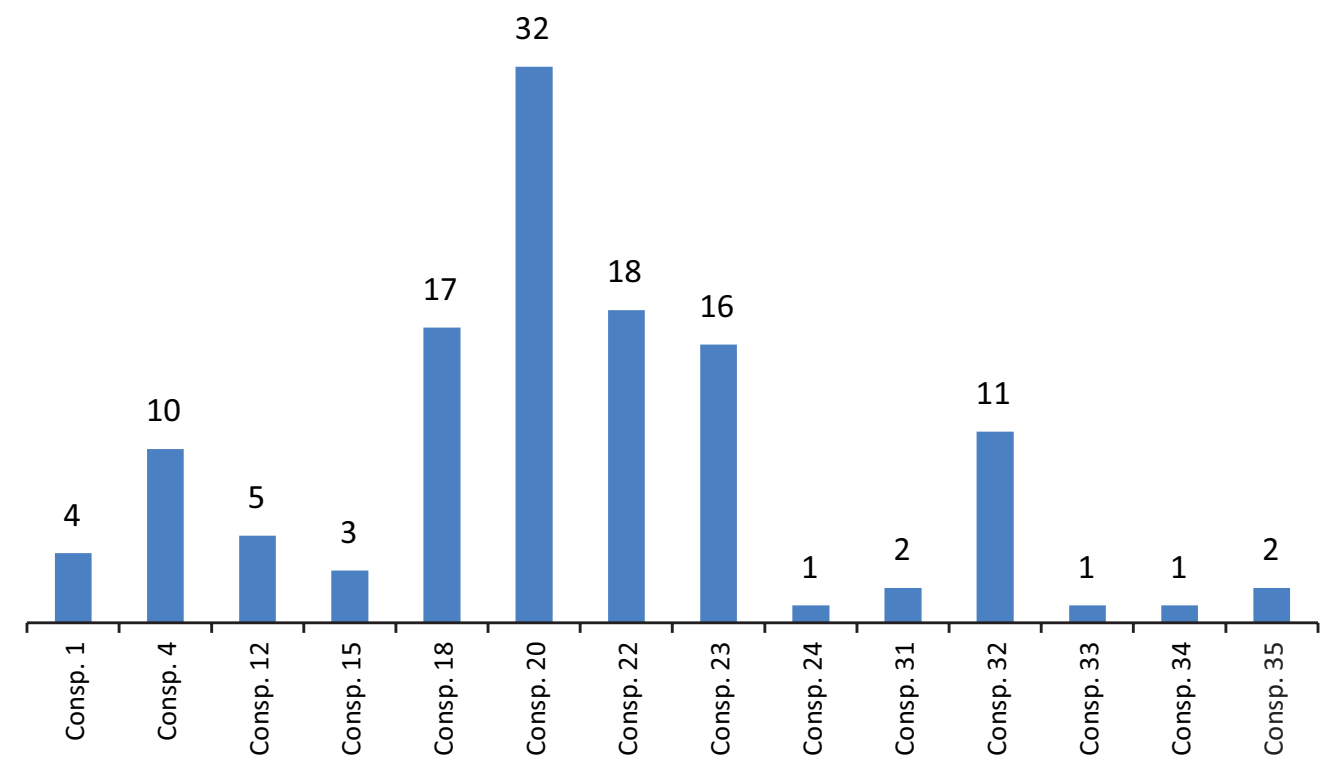

Figura 7. Número de fragmentos de formas de terra sigillata itálica lisa.

exvasadas con borde de sección semicircular (fig. 8, 1). Aunque en una proporción relativamente reducida, la presencia de esta forma podría indicar que la TSI podría haber alcanzado la ciudad de Aeminium todavía antes del año 15 a.C.; dato realmente interesante, ya que en la vecina Conimbriga no se conocen importaciones itálicas anteriores al año 10 a.C. (Delgado et al. 1975: 13-19).

De hecho, será en torno a este momento (15-10 a.C.) cuando comience a crecer el volumen de importaciones de TSI, aunque todavía de forma poco expresiva como se demuestra por la poca presencia del plato Consp. 12.1 (fig. 8, 8), cuya cronología propuesta apunta hacia un período corto de producción entre el año 15 y 10 a.C., de las variantes más tardías (pequeñas y con paredes menos abiertas) integrables en la forma Consp. 12.4 (fig. 8, 6-7) que aun así no sobrepasan el reinado de Augusto.

Aunque tradicionalmente asociados a este grupo de formas designadas como clásicas, los platos integrados genéricamente en la forma Consp. 4 abarcan un período de producción bastante largo. Gran parte de los ejemplares de esta colección parece corresponder a una de las variantes más tardías (Consp. 4.6) (fig. 8, 3-5), que puede alcanzar la mitad del siglo I (Ettlinger et al. 1990: 58). Sin embargo, debe apuntarse la presencia de variantes más antiguas como un fragmento que parece corresponder a la forma Consp. 4.4 (fig. 8, 2) y que no debe sobrepasar la primera década del siglo I d.C. y, otro, integrado en la forma Consp. 4.5 (fig. 8, 4) que podría llegar hasta los finales del reinado de Augusto (Ettlinger et al. 1990: 58).

Todavía encuadrables en este período son los tres fragmentos de la copa campaniforme de borde convexo de la forma Consp. 15.1 (fig. 9, 1). Con la excepción de la ausencia del habitual guillochis en el borde, los ejemplares identificados presentan el resto de características de esta copa cuyo arranque productivo se centra en los años 5-3 a.C. (Goudineau 1968: 299-300; Ettlinger et al. 1990: 78-79).

Los productos fechables a finales del reinado de $\mathrm{Au}-$ gusto y en el reinado de Tiberio, momento que podemos encuadrar en los finales de la fase "clásica" y los inicios de la fase "avanzada", son los mayoritarios en el conjunto. Será en este período en el que se alcance un mayor volumen de importaciones, donde destacan los platos de las formas Consp. 18 y 20 y las copas de su servicio - Consp. 22 y 23; una situación que se verifica, de igual forma, en otros yacimientos del territorio portugués como Conimbriga (Delgado et al. 1975: 13-19), Bracara Augusta (Morais 2005: 160-162 y fig. 40) o Santarém (Viegas 2003: 44-46). En Aeminium, el conjunto de estas formas supone un $67,5 \%$ del total de los perfiles identificados.

El plato de la forma Consp. 18 parece estar presente en este conjunto exclusivamente en su variante más común-Consp. 18.2- que se distingue por su moldura 
externa del borde (fig. 8, 9-10). Se sugiere para esta variante la última década del siglo I a.C. como fase inicial de su producción (Goudineau 1968: 305; Ettlinger et al. 1990: 82), teniendo una mayor incidencia durante los reinados de Augusto y Tiberio, cuando evoluciona hacia la forma Consp. 20 con un perfil más simple.

El plato Consp. 20 es, de lejos, la forma más numerosa del conjunto, reconociéndose las formas más tardías (Consp. 20.4 y 20.5), normalmente más abundantes, presentes en contextos que pueden alcanzar los decenios centrales del s. I d.C. (Ettlinger et al. 1990: 86). De hecho, también en este lote se verifica el predominio de la variante Consp. 20.4 que se corresponde, excepto dos fragmentos, con la totalidad de este tipo de platos. Estos ejemplares presentan, por norma, paredes rectas y finas, remarcadas por molduras bien ejecutadas (fig. 8, 11-12) y, en algunos ejemplares, decoración aplicada (fig. 8, 13-14) siendo esta una de sus características. Se documenta también un plato de paredes ligeramente curvadas y sin subdivisión interna integrable en la variante Consp. 20.3 (fig. 8, 16) y otro con una triple moldura que podría perfectamente encuadrarse en la variante Consp. 20.5 (fig. 8, 15).

La forma Consp. 22 inicia la secuencia de las copas, correspondientes a los platos anteriormente descritos (Consp. 18 y 20), del designado como servicio II de Haltern. La copa de perfil cónico cuya cronología se encuentra entre mediados del reinado de Augusto y el reinado de Tiberio (Ettlinger et al. 1990: 90), es muy frecuente en el territorio portugués. Es la forma más abundante en Alcáçova de Santarém (Viegas 2003: $63-$ 66), siendo de las más comunes en Conimbriga (donde se corresponde con la forma 27 de Goudineau-Delgado et al. 1975: 16 y pl. V-VI, no 101-117) tal y como sucede en Aeminium. La división interna del borde que se observa en nuestras piezas parece situarlas en la fase inicial de la producción, encontrándose representadas las variantes Consp. 22.1 (fig. 9, 3-4) y Consp. 22.2 (fig. 9, 2). En el final del reinado de Tiberio, su perfil se simplifica hacia la forma Consp. 23. Este es el motivo de la dificultad a la hora de distinguir las variantes más tardías de la forma Consp. 22 y las más antiguas de la forma Consp. 23. Admitimos por lo tanto ciertas dificultades en la clasificación de un fragmento que finalmente se integró en la forma Consp. 22.5 (fig. 9, 5).

Del mismo modo, fundamentamos la clasificación de las piezas de la forma Consp. 23 en la verticalidad de la pared superior, sin divisiones internas, que contrasta con el perfil troncocónico de la copas Consp. 22. Nótese además que las pequeñas dimensiones de ciertos fragmentos no posibilitaron una clasificación segura, admitiéndose que puedan integrar las diversas variantes de Consp. 22. Destacamos una pieza con decoración aplicada con el motivo de una doble espiral (fig. 9, 7), que sugiere una cronología en torno a la segunda década del siglo I d.C. (Ettlinger et al. 1990: 92).

Contemporánea a las formas anteriores (Consp. 22 y 23) y relativamente frecuente en contextos augusteos y tiberianos (Ettlinger et al. 1990: 94-95), se registra la presencia de un fragmento próximo a la variante $1.3 \mathrm{de}$ la forma Consp. 24, a pesar de faltarle el característico resalte interno (fig. 9, 8).

Por su parte, la forma Consp. 31 inicia un conjunto de copas (Consp. 31 a 38), integradas en una fase tardía, que presentan diversas soluciones en el borde y en el perfil de la pared. El ejemplar representado (fig. 9, 9) presenta un perfil biconvexo y decoración de ruedecilla en el borde, por lo que parece un producto de finales de Augusto y de los inicios de Tiberio (Ettlinger et al. 1990: 106).

La copa Consp. 32 se encuentra bien representada en los contextos del forum (fig. 9, 10-11). A pesar de surgir con la forma anterior, presenta una fase productora más amplia que podría alcanzar el reinado de Tiberio (Ettlinger et al. 1990: 108). Aunque se aprecian pequeñas variaciones en el borde (uno con decoración aplicada), el perfil completo de nuestra pieza (fig. 9, 12) nos aporta una serie de particularidades que nos llevan a incluirla en la variante 1 de la forma Consp. 32 .

La copa hemisférica Consp. 33 solo cuenta con un ejemplar decorado con ruedecilla (fig. 9, 13). Su perfil elaborado no dificulta su integración en las variantes de la forma. No obstante, la moldura exterior parece asociarla a la forma Goud. 38 en su variante más tardía (a), que comienza a producirse antes del año 16 a.C. (Goudineau 1968: 305-306).

El resto de copas identificadas, una Consp. 34 (fig. 9, 14) y dos Consp. 35 (fig. 9, 15), podrán incluirse en una cronología más tardía, siendo producidas a partir de finales del reinado de Tiberio (Ettlinger et al. 1990: 112).

Ante la imposibilidad de realizar análisis de laboratorio de las piezas itálicas que determinasen su origen concreto, el estudio de las marcas de alfarero es, también aquí, un importante indicador. A pesar de ello, como se sabe, la atribución de los centros productores con base en este aspecto podría levantar dudas. De cualquier modo, las cuatro marcas identificadas parecen sugerir una ligera hegemonía de los productos oriundos de Arezzo y sus sucursales.

De hecho, en dos de los fragmentos identificamos una marca que atribuimos a la oficina de Publius Cornelius de Arezzo. En territorio portugués es uno de los 
alfareros con mayor volumen de producción atribuida, aunque tal vez debiese ser matizada por su gran longevidad productora. Al contrario de la mayor parte de los alfareros itálicos que cesan su actividad antes del año 10 d.C., las oficinas de este productor sobreviven hasta el año 40 d.C. (Silva 2005: 99). Uno de los fragmentos posee en el exterior del fondo (?) una cartela rectangular de ángulos rectos con una marca bilineal, donde se señala con letras bien definidas y separadas por una línea auxiliar la siguiente firma: [QUARTIO / P.COR] (fig. 9, 16). La lectura de la segunda línea [P.COR] no presenta dificultades al tratarse de una abreviatura muy común en las oficinas de Publius Cornelius. Por otro lado, en la primera línea, el corte superior verificado en las últimas letras nos presenta, en un primer análisis, algunas dificultades de lectura. Sin embargo, estamos convencidos de que se trata de la impresión de un punzón relativo a uno de los "dependientes", tal vez de estatus servil, de este alfarero, de nombre Quartius. Este se encuentra registrado en el catálogo de Hofmann (1985: Arezzo, pl. IX, $\mathrm{n}^{\circ}$ 125). La forma de la marca, una cartela rectangular de dos líneas separada por un trazo (OCK 261), es utilizada sobre todo en época de Augusto (Silva 2005: 110). La marca detectada en el segundo de los fragmentos presenta algunos problemas. Se localiza en el fondo interno en una cartela semicircular incompleta (fig. 9, 17). La primera lectura nos sugiere [(...) PCOI]. La primera y última letra no presenta lectura segura por lo que aventuramos la hipótesis de que la última letra pueda ser una $\mathrm{R}$, lo que daría una de las abreviaturas más habituales de Publius Cornelius.

Otra de las marcas también está incompleta, con cartela rectangular de ángulos redondeados, con la marca [ZOIL (...)] (fig. 9, 18). Zoilus es uno de los libertos de Cneus Ateius, uno de los alfareros itálicos con mayor volumen y diversidad de producción. Aunque aparece habitualmente con tria nomina, o asociado a Xanthus o a Mahes, aparece aquí solo con el cognomen, característica esta que podría indicar una fase de fabricación más antigua. La existencia de marcas relacionadas con el "círculo de Ateius" en producciones localizadas en Arezzo, Pisa y La Muette-Lyon generan alguna controversia parcialmente resuelta al probarse la transferencia de sus oficinas de Arezzo a Pisa en torno al año 5 a.C. (Kenrick 1997: 186).

Finalmente contamos con un sello completo, en cartela ligeramente ovalada, con la marca [IVN] (fig. 9, 19) relativo a Iunius. Suele ser habitual la presencia en la península ibérica de su homónimo gálico aunque en este caso, sus características nos llevan a incluirla como una producción de Pozzuoli, también documentada en territorio portugués (Alarcão 1971: 431; Diogo 1980: $\left.n^{\circ} 107\right)$.

\subsubsection{Terra sigillata sudgálica}

En el caso de las producciones sudgálicas, los 119 fragmentos a los que fue posible atribuirles forma se encuentran repartidos entre formas lisas y decoradas, representando las primeras un $94,1 \%$ y las segundas apenas un 5,9\% del total. En ambos casos, se verificó la presencia casi exclusiva de formas de imitación de prototipos itálicos, integrables en las fases productivas designadas como primitiva y de esplendor, con una cronología fijada, respectivamente, entre 20-40 y 40-60 d.C. (Vernhet 1979: 18).

La observación macroscópica de sus características de pasta y barniz parece revelar, como sucede en otros lugares de la zona centro-norte de la Lusitania (cf. el caso de Conimbriga: Delgado et al. 1975: 69), una proveniencia exclusiva, o casi exclusiva, de las producciones de La Graufesenque.

Las formas lisas se encuentran repartidas por un grupo de formas que consideramos representativo de las fases en cuestión, comprobándose una supremacía de las copas (63 fragmentos) frente a los platos (49 frag.). Entre las primeras, destaca la presencia mayoritaria de la forma Drag. 27 (23 frag.), seguida por las formas Drag. 24/25 y Ritt. 5 (cada una representada por 14 frag.), Ritt. 8 (9 frag.) y Ritt. 12 (3 frag.). El grupo de los platos está dominado por la forma Drag. 15/17 (28 frag.), estando igualmente representados ejemplares de la forma Drag. 18 (Drag. 18/31 - 11 frag.), Ritt. 1 (7frag.), Drag. 17b (2 frag.) y Drag. 2/21 (1 frag.) (fig. 10).

La forma Drag. 27 (fig. 9, 1-2), tal como sucede en otros yacimientos (Viegas 2003: 115-116), es la más numerosa dentro del grupo de las copas. De tradición itálica pero ya sin su característica ruedecilla, estas copas se pueden fechar durante un amplio período que comienza durante el principado de Tiberio (Martin y Garnier 1977: 158; Bourgeois y Mayet 1991: 87-88; Genin 2007: 325). Los fragmentos estudiados presentan barnices de buena calidad, adherente y brillante, y se corresponden con piezas de pequeño diámetro, en torno a los $80 / 85 \mathrm{~mm}$, con perfiles integrables en la variante 27A, propias de la fase pre-flavia de la producción.

La forma Ritt. 5, inspirada en la forma Consp. 22, es relativamente abundante en este conjunto del foro, al documentarse tres perfiles diferentes (fig. 11, 3-5). Uno de ellos, por la configuración de su borde, el perfil anguloso 
1

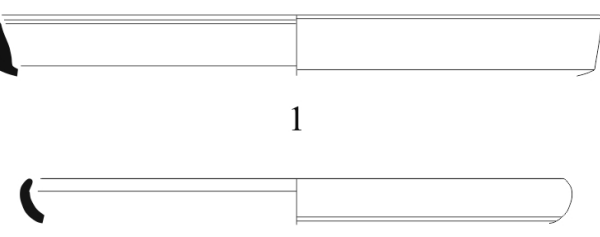

3

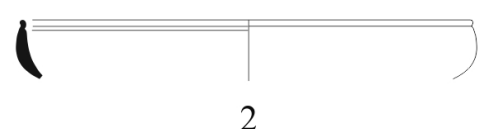

2

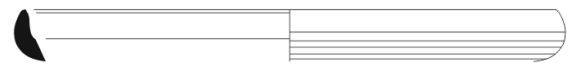

4

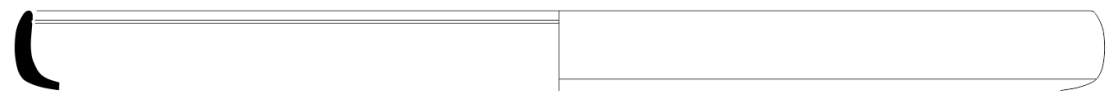

5
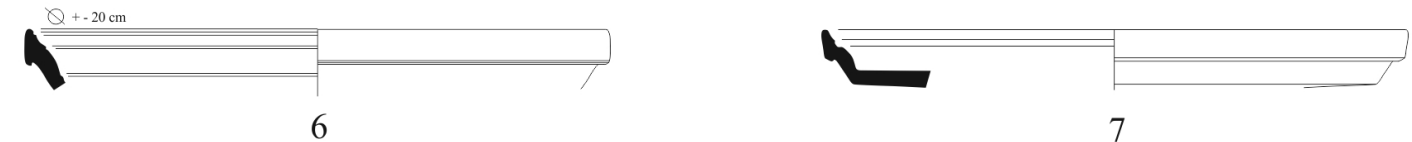

7

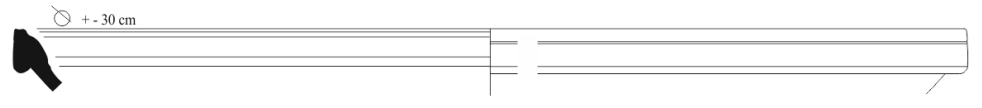

8

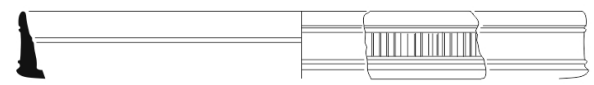

9

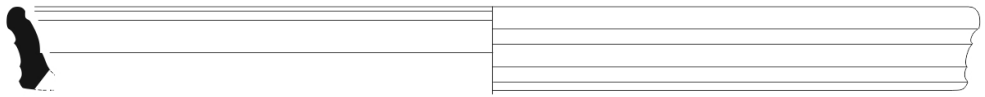

10

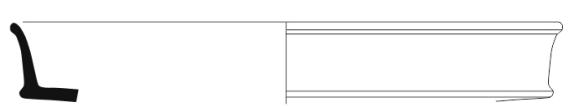

11

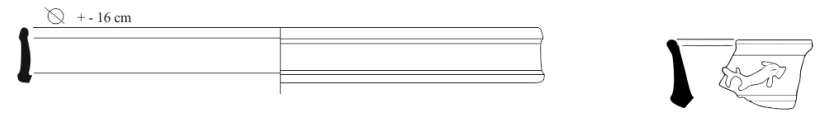

12

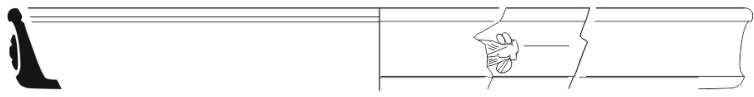

14

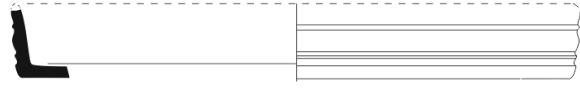

15
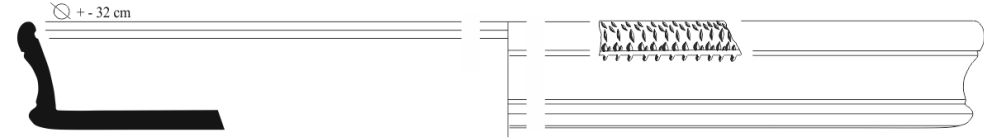

16

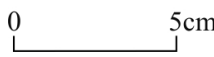

Figura 8. Terra Sigillata Itálica de los contextos del complejo forense de Aeminium. 


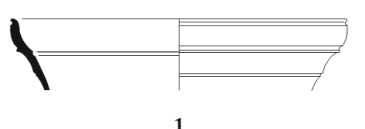

1

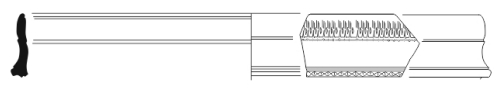

3
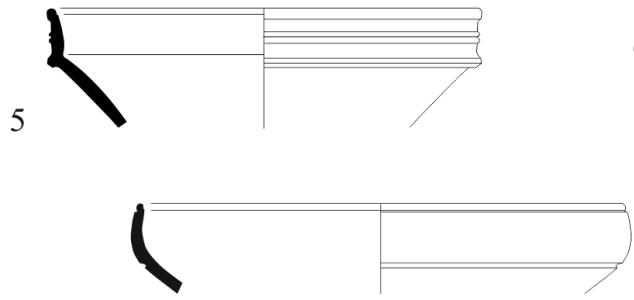

8

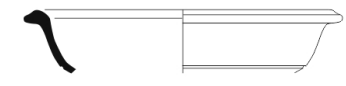

10

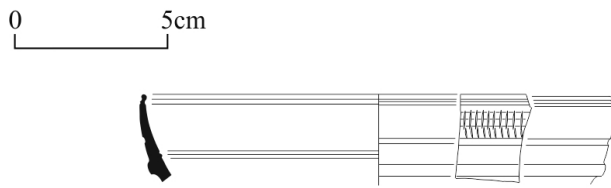

13

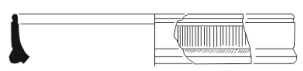

14
15

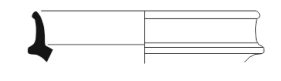

6

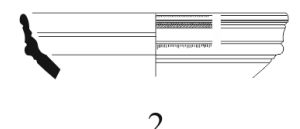

2

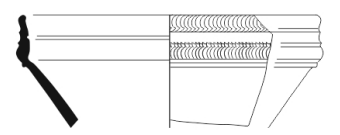

4

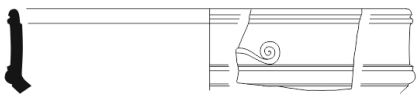

7

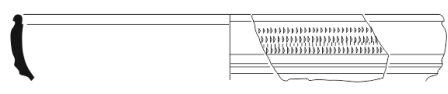

9

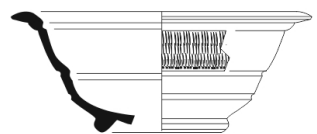

12 (20x)

16
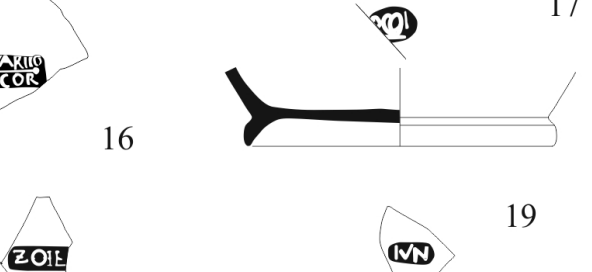

ZOIE

18
19

Figura 9. Terra Sigillata Itálica de los contextos del complejo forense de Aeminium.

y la decoración aplicada (fig. 11, 3) se aproxima a los prototipos itálicos. Aunque ampliamente distribuida durante el reinado de Tiberio, debido sobre todo al éxito de su modelo itálico, el final de su fabricación parece producirse en torno al año 40 d.C. (Genin 2007: 324).

La forma Drag. 24/25 también está bien representada en este conjunto, documentando en los ejemplares ilustrados (fig. 11, 6-8), una amplia variabilidad formal y de diámetros. La producción de esta forma, iniciada con Tiberio, ha conocido pocas variaciones aunque se observa una cierta preferencia a finales del siglo I, por las piezas con dimensiones más pequeñas (Martin y Garnier 1977: 155 y 181; Genin 2007: 326). Por consiguiente, atendiendo a sus dimensiones, algunos ejemplares podrían incluirse en una variante antigua, fechada en el reinado de Tiberio (fig. 11, 7), mientras que para otros se le atribuye una datación en el reinado de Claudio, sin sobrepasar la década de los 50 (fig. 11, 6). La buena calidad del barniz y la presencia de la decoración a ruedecilla parecen refrendar esta teoría.

Entre las tazas, con su típico perfil hemisférico, se documenta la forma Ritt. 8. Los fragmentos identificados presentan variaciones aunque es predominante el perfil del ejemplar ilustrado (fig. 11, 9), pudiendo encuadrarse perfectamente dentro de los contextos de época claudia (Genin 2007: 328). 


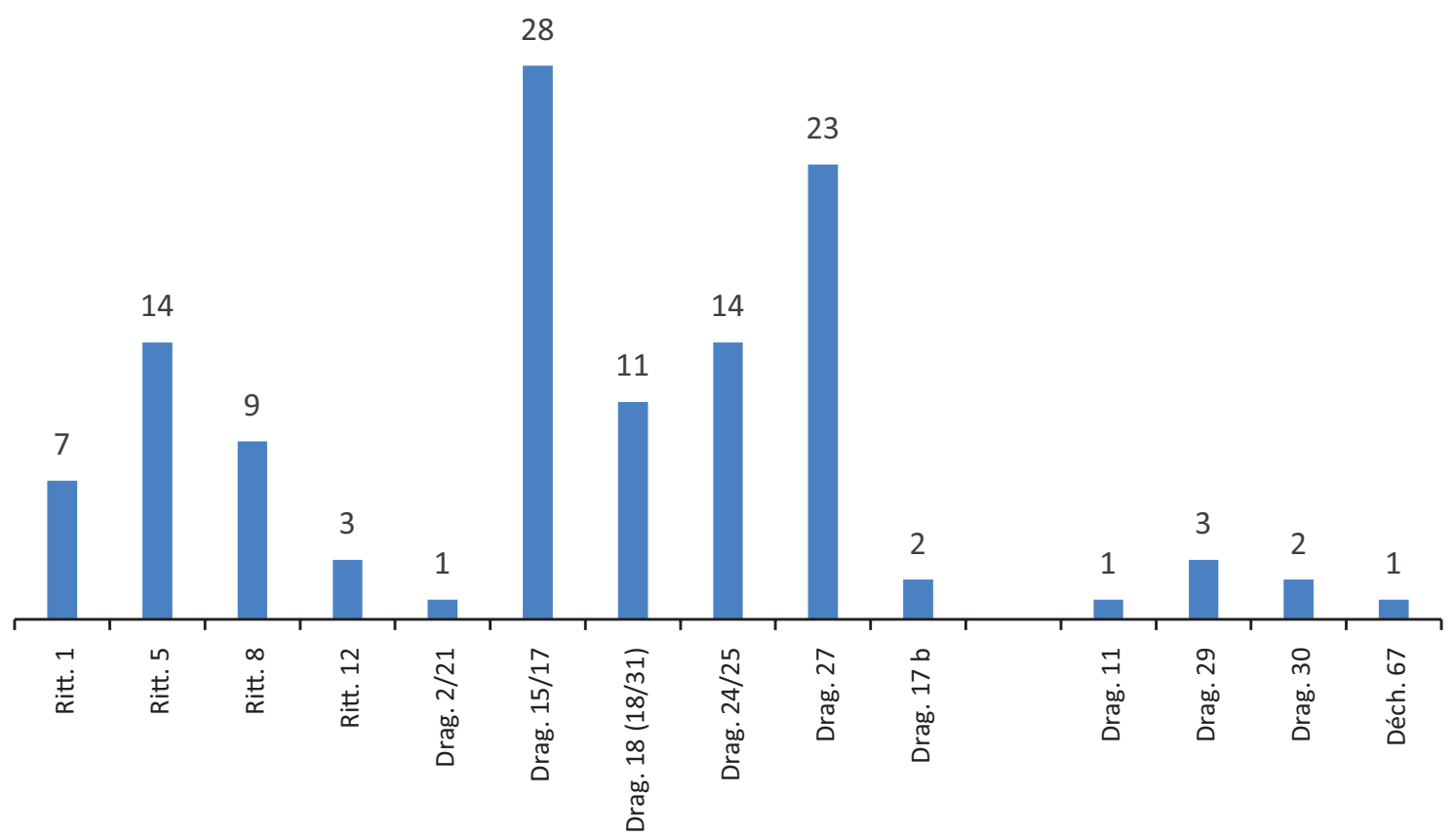

Figura 10. Número de fragmentos de formas de terra sigillata sudgálica.

La identificación de tres fragmentos de la forma Ritt. 12 (fig. 11, 10), correspondiente con un cuenco (evolucionado de prototipos de mortaria itálicos augusteos: Oswald y Pryce 1966: 210-211), acentúa la diversidad de la importaciones del sur de la Galia en Aeminium. Esta forma debió ser exportada en bajas cantidades, conforme se puede testar de su pobre representación en otras ciudades romanas de la Lusitania y la Gallaecia: como ejemplo, Bracara Augusta con dos fragmentos registrados (Morais 2005: 197, $\mathrm{n}^{\circ}$ 205 y 206), Conimbriga (Delgado et al. 1975: 94, Est. XXIX, n 231) o Santarém (Viegas 2003: 120) solo con un ejemplar. Esta forma parece producirse entre 30/40 y 70/80 d.C. (Genin 2007: 327), siendo los ejemplares de Aeminium, por sus pequeñas dimensiones, sus barnices brillantes y adherentes o la ausencia de decoración, posiblemente de la fase inicial de la producción.

Al igual que las copas y cuencos, también en los platos se verifica la presencia de un conjunto relativamente diverso de formas.

Los platos Drag. 15/17 son los más numerosos de todo el conjunto gálico. Inspirándose en modelos itálicos, la forma presenta una cronología productiva amplia entre Tiberio y los inicios del siglo II (Vernhet 1986: 100; Bourgeois y Mayet 1991: 82, fig. 5 y 100-101; Genin 2007: 333-334). Las piezas analizadas, debido a la buena calidad de su barniz y sus perfiles (fig. 11, 11-12), con bordes moldurados cortos y abiertos, pueden asociarse a una fase inicial de la producción, incluyendo el designado como período de "esplendor", entre circa 40 a 60 d.C.

Del conjunto de los platos, se aislaron siete individuos, con perfil semejante, de pared cóncava que parecen corresponder a la forma Ritt. 1 (fig. 11, 13-14). También de tradición itálica, se trata de una forma precoz de la producción, encuadrable en el segundo cuarto del siglo I d.C. (Vernhet 1986: 100; Bourgeois y Mayet 1991: 82, fig. 5 y 96-97), y sin sobrepasar la década de los 60/70 -período pre-flavio (Genin 2007: 334), aunque en este caso, sus características permiten situar a estos ejemplares en el período claudio.

Particularmente comunes parecen ser los platos de la forma Drag. 18 (18/31), aunque en este conjunto aparezcan muy fragmentados (fig. 11, 15). La producción de esta forma, con sus múltiples variantes, se inscribe entre el reinado de Tiberio y los inicios del siglo II (Lutz 1974: 35; Delgado et al. 1975: 93; Bourgeois y Mayet 1991: 82 y 101-102; Genin 2007: 332).

Uno de los individuos de más difícil clasificación, debido a sus reducidas dimensiones, parece corresponderse con un plato de borde curvo y vertical, identificado como un individuo de la forma Drag. 2/21 
(fig. 11, 16), forma con una datación comprendida entre 15/20-60/70 d.C. (Genin 2007: 334-335). Una datación similar ofrecen dos individuos de la forma Drag. 17B (fig. 11, 17), con semejanzas en las variantes tardías del modelo itálico Consp. 20.4.

Las piezas decoradas, a pesar de no ser numerosas, pertenecen a buenas producciones y presentan una diversidad morfológica importante, si atendemos a la totalidad de las piezas identificas (apenas siete ejemplares) y al período temporal en el que se inscriben. No obstante, sus reducidas dimensiones y/o al hecho de no corresponderse a fragmentos de borde (dificultando su clasificación tipológica), creemos contar con la representación de las formas más comunes de la La Graufesenque: p.ej. el cuenco carenado Drag. 29 y el cuenco Drag. 30, además de un individuo de la forma Drag. 11 y otro, probablemente, de la forma Déch. 67.

De hecho, uno de los ejemplares podrá corresponderse al pie de un cáliz de la forma Drag. 11 (fig. 11, 2), representando la forma decorada más antigua, nítidamente influenciada por los caliciformes itálicos, que se fecha genéricamente en la dinastía jJulio-Claudia (Martin y Garnier 1977: 171; Fiches 1977: 133-134).

A pesar de sus reducidas dimensiones, creemos poder clasificar tres fragmentos de la forma Dra. 29. El primero (fig. 11, 21) se corresponde con la parte inferior de una pared en el que se vislumbra una arcada y posibles guirnaldas ondulantes. El segundo (fig. 11, 20), por su parte, presenta un listel con hiladas de perlas a ambos lados. El último (fig. 11, 22) presenta una hilada de perlas limitando tallos rematados en hojas de hedera. Estos cuencos, en sus diversas variantes, dominan la producción decorada en el período julio-claudio siendo sustituidas paulatinamente por el cuenco Drag. 37 (Fiches 1978: 44; Bourgeois y Mayet 1991: 82; Delgado et al. 1975: 73-74), forma ausente en este contexto.

El cuenco cilíndrico Drag. 30 podrá estar representado por dos fragmentos (no ilustrados) de paredes rectas y finas, en cuya superficie se vislumbra un cordón de perlas. La cronología de esta forma es muy amplia, entre el 30/40 d.C. hasta los inicios del siglo II d.C., siendo habitual en Conimbriga en contextos de mediados y del tercer cuarto del siglo I d.C. (Bourgeois y Mayet 1991: 82; Delgado et al. 1975: 73).

Por último, destaca entre las formas decoradas un fondo con engobe del tipo marmorata decorado por una serie de escamas sobrepuestas (fig. 11, 19). Habitualmente este tipo de producción es considerado exclusivo de La Graufesenque, contando con un corto período de producción entre el 40 y el 70 d.C. (Vernhet 1986: 102). Su morfología nos lleva a encuadrarlo en la forma Déch. 67, también identificada en Conimbriga (Delgado et al. 1975: 74).

El conjunto solo contaba con dos fragmentos de fondo con marca de alfarero. En ambos casos, provienen de la oficina de Crestus (o Crestio), de La Graufesenque, ya documentada en territorio portugués (Silva 2005: anexo B) y cuyo inicio de producción se fecha en época de Claudio-Nerón (Oswald 1983: 95-96; Hofman 1985: 16 (n. ${ }^{\circ}$ 46); Bémont 1976: 99; Polak 2000: 213-216; Genin 2007: 263; Hartley y Dickinson 2008: 189). En los sellos, ambos incompletos y en cartela rectangular de ángulos redondeados, se puede leer en uno de los casos [CREST (...)] (fig. 11, 24) y, en el otro, [CRESTI (...)] (fig. 11, 23), pudiendo integrarse en el grupo de marcas tipo 5a o 5b de R. Hartley y B.M. Dickinson (2008: 188). La ausencia de sellos en la mayoría de los fragmentos de fondo recuperados dificulta la atribución de una cronología más precisa para las formas representadas. No obstante, la asociación de las formas entre sí, además del contexto o posición estratigráfica, sirve de soporte para la propuesta cronológica.

\section{3. Ánforas}

El conjunto anfórico recuperado en los niveles de aterrazamiento coetáneos a la ampliación del complejo forense, aunque relativamente escaso, constituye una muestra suficientemente representativa del patrón de importaciones de la ciudad de Aeminium y su región circundante durante los períodos tardorrepublicano y julioclaudio. De hecho, se trata de un conjunto de materiales que, incluso sin presentar una cronología idéntica, participan de la homogeneidad del contexto arqueológico en el que se encuadran. Si parte de las producciones hispánicas identificadas (ánforas de los tipos Dr. 14, Dr. 7/11 y Haltern 70) son perfectamente integrables en la época de ampliación del foro, las producciones itálicas y los productos precoces hispánicos representan un horizonte cronológico diferente, más antiguo, sin dejar de ser también elementos encuadrables, en la medida en que son interpretados como materiales residuales. Sin embargo, tanto unas como otras se revelan como importantes indicadores económico-comerciales para una región en la que la escasez de este tipo de productos es la característica dominante. Las primeras muestran la vitalidad y un claro predominio, probablemente desde mediados del siglo I d.C., de las importaciones béticas de vino, aceite y preparados piscícolas. Las segundas, de cronología tardorrepublicana, asumen una especial relevancia dada la asociación que debió existir entre la 

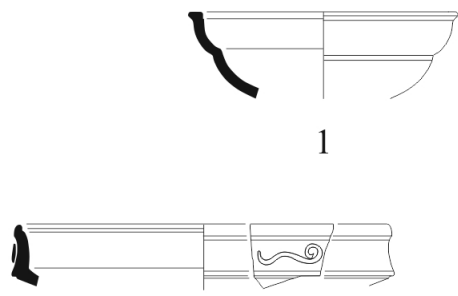

3

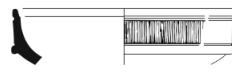

6

0 $5 \mathrm{~cm}$
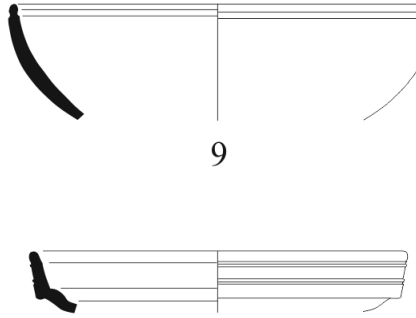

11

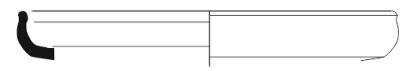

13

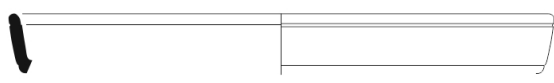

15

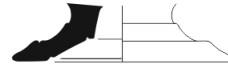

18

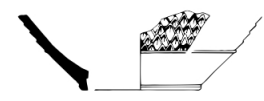

19

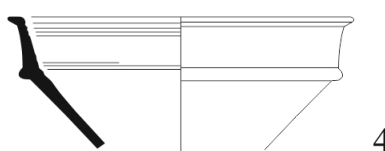

4
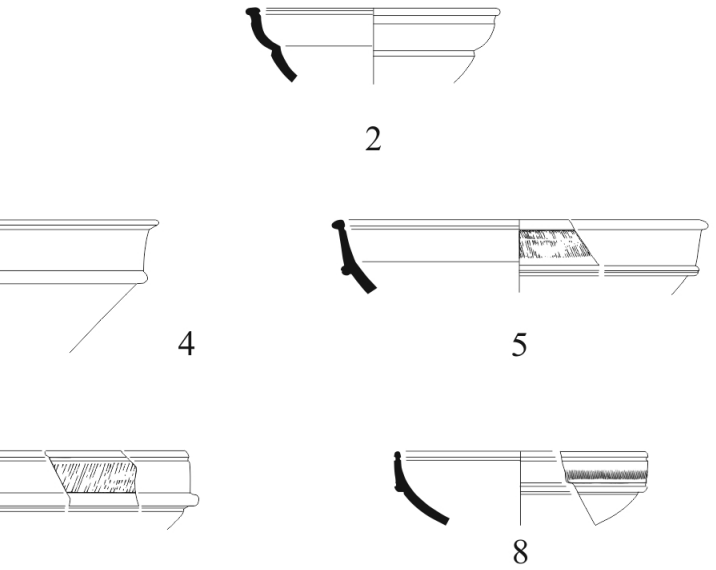

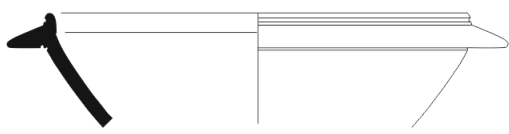

10

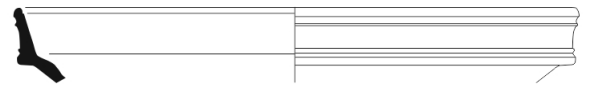

12

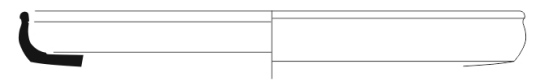

14

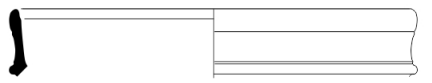

17
16

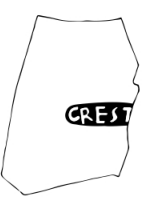

CRESTh

24

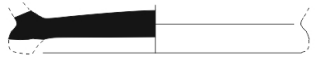

0

$5 \mathrm{~cm}$

Figura 11. Terra Sigillata Sudgálica de los contextos del complejo forense de Aeminium. 


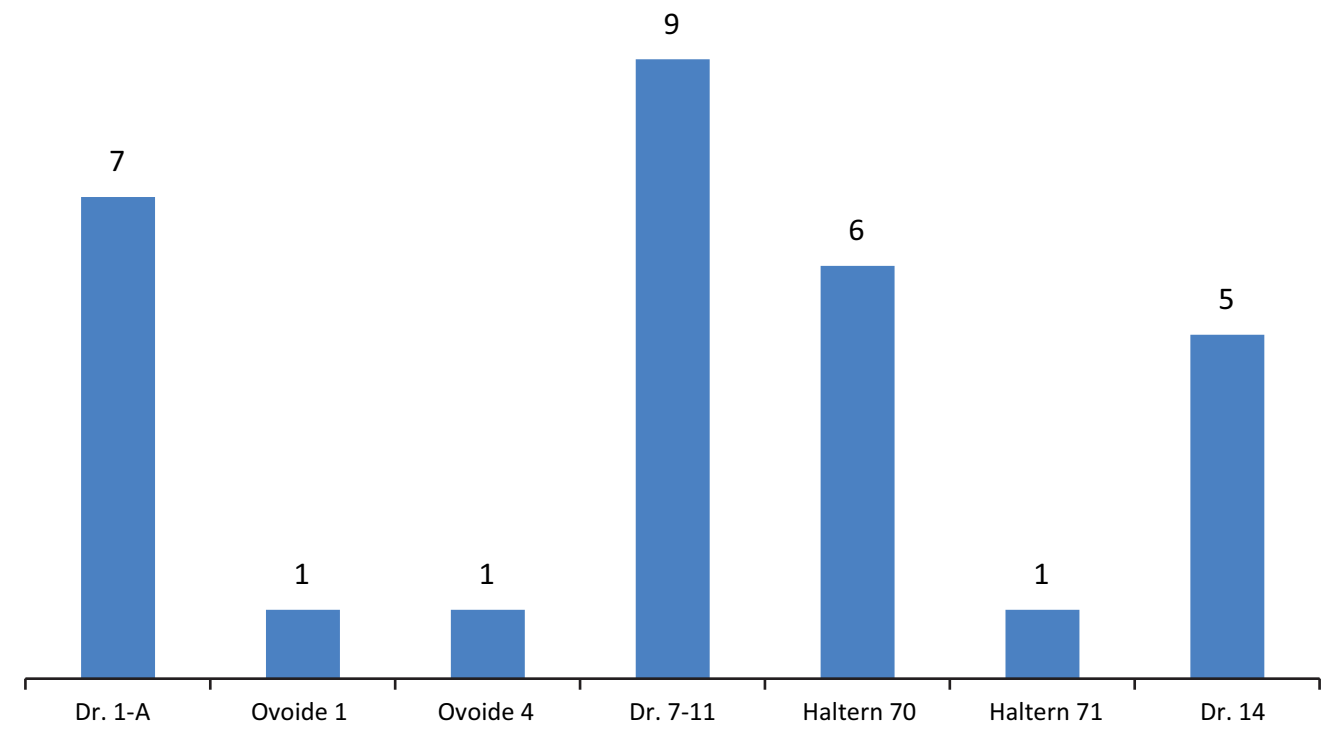

Figura 12. Número de los diferentes tipos de ánforas.

importación de estos contenedores y las campañas militares de conquista y ocupación de Décimo Junio Bruto (Fabião 1989: 110-111 y 115).

El conjunto anfórico no es particularmente numeroso. De los poco más de cien fragmentos solamente se pudieron clasificar 30 individuos. Los restantes son fragmentos informes de pared y algunos restos de asas y pivotes de tan reducido tamaño, que imposibilitó su adscripción tipológica. Destaca de modo general el predominio de las ánforas vinarias itálicas del tipo Dressel 1A, las multiproducto Haltern 70 y los contenedores salsarios del tipo Dressel 7-11 (fig. 12).

Es particularmente expresiva la presencia de fragmentos del contenedor Dr. 1, predominando los individuos con el borde de perfil triangular y pendiente (fig. 13, 1-3) frente a los ejemplares con el borde oblicuo y más voluminoso (fig. 13, 2), integrados ambos en la variante A de la forma. Destinadas sobre todo al transporte de vino itálico, parecen comenzar a producirse en el último tercio del siglo II a.C., siendo progresivamente sustituidos por otros contenedores durante la segunda mitad del siglo I a.C. (Benoit 1957: 264; Zevi 1966: 212-214; Desbat 1998), pudiendo estar asociadas en nuestro territorio, en una fase inicial del proceso de ocupación romano, al abastecimiento del ejército (Fabião 1989: 111, 115 y 125).

También en época tardorrepublicana se deben fechar dos contenedores béticos. Uno de ellos presenta un borde ovalado con resalte en el inicio del cuello atribuible al tipo Lomba do Canho 67 (fig. 13, 4). Este tipo de ánforas, que fueron definidas y agrupadas por C. Fabião (1989), se inserta en el grupo de los contenedores ovoides béticos fabricados durante el siglo I a.C., constituyéndose como una de las más antiguas producciones de esta región (Fabião 1989: 65-68; Fabião 2000: 667; Almeida 2006: 48). Actualmente, dentro de la tipología en uso de los contenedores ovoides béticos, este ánforas se encuadra en el tipo "Ovoide 1" (García Vargas et al. 2011). Se documenta su presencia por todo el territorio portugués, también en el Noroeste peninsular e incluso en el Mediterráneo, aparentemente en contextos fechados desde el 70 a.C. hasta inicios del siglo I d.C. (González Cesteros et al. 2013), siendo su presencia mayor en niveles del tercer cuarto del siglo I a.C. (Fabião 1989: 68; Molina Vidal 2000: 640).

El otro ejemplar lo incluimos, con ciertas reservas, dentro de la tipología Ovoide 4 del Guadalquivir (fig. 13, 5). Este tipo de envases, antecedentes directos de la Haltern 70, se fechan en la República tardía, en concreto entre el 70 y el 15 a.C. (García Vargas et al. 2013).

El grupo más abundante del conjunto anfórico lo conforman contenedores que podemos datar prácticamente en el cambio de Era y durante todo el siglo I d.C., protagonizado por contenedores béticos y lusitanos, entre los que encontramos los tipos Dressel 7/11, Haltern 70, Haltern 71 y Dressel 14.

Destaca la presencia significativa de los contenedores salsarios béticos del tipo Dressel 7/11 (fig. 13, 9-13) 


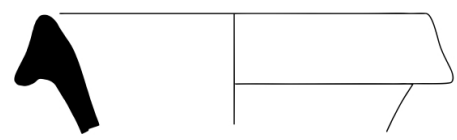

1

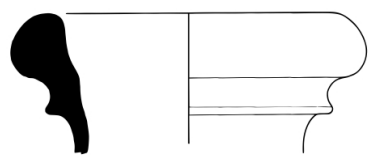

4

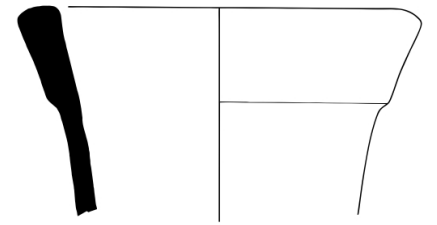

7
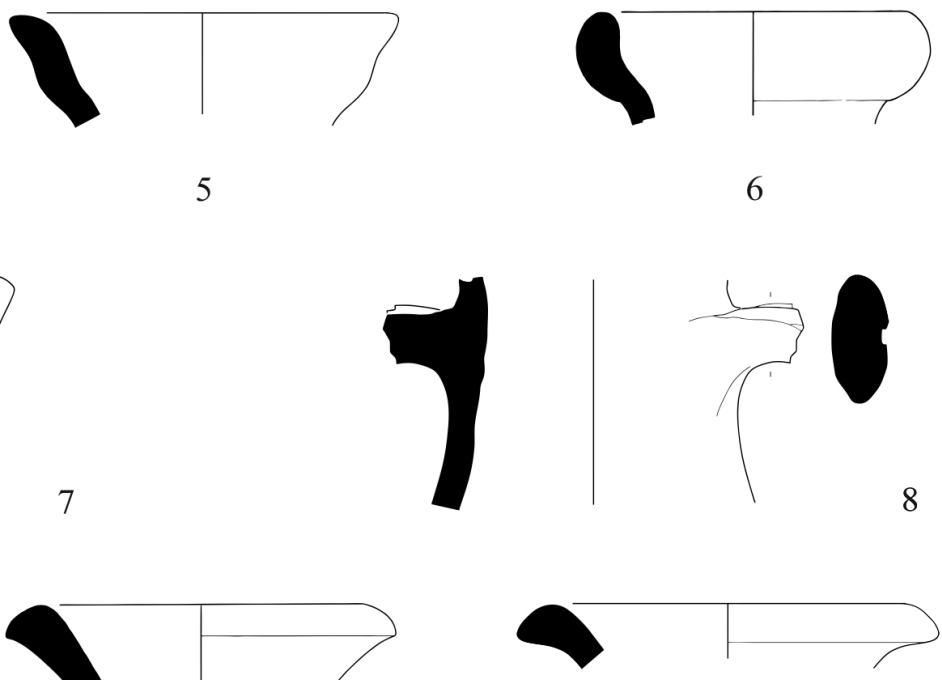
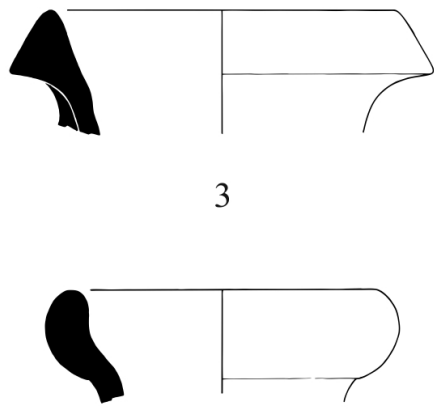

6

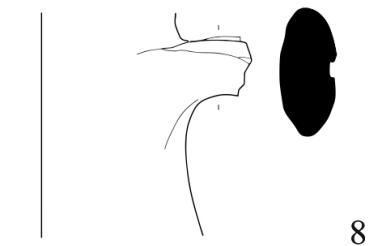

8

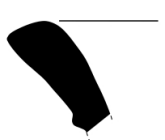

10

9

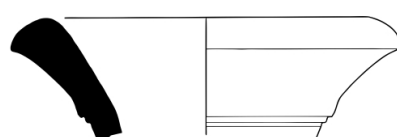

11

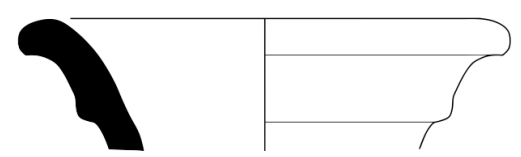

12

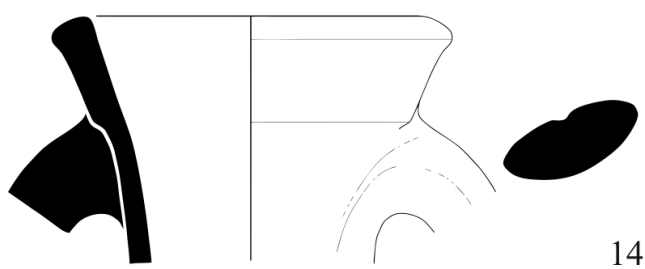

Figura 13. Ánforas de los contextos del complejo forense de Aeminium.

y, en menor medida, los lusitanos del tipo Dressel 14 (fig. 13, 14-15). La producción de estos contenedores, tanto los béticos como los lusitanos, se debe situar a inicios del siglo I d.C. o incluso un poco antes, substituyendo a modelos ovoides tardorrepublicanos y prolongándose su uso durante todo el siglo I e inicios del siglo II d.C.
Destáquense también algunos fragmentos de ánforas Haltern 70 (fig. 13, 7-8). Sin entrar en la problemática de su contenido/s, debemos señalar su aparición durante la segunda mitad del siglo I a.C., substituyendo paulatinamente a su predecesora "Ovoide 4" y siendo en época julio-claudia cuando este tipo alcance su auge productivo y de difusión (Colls et al. 


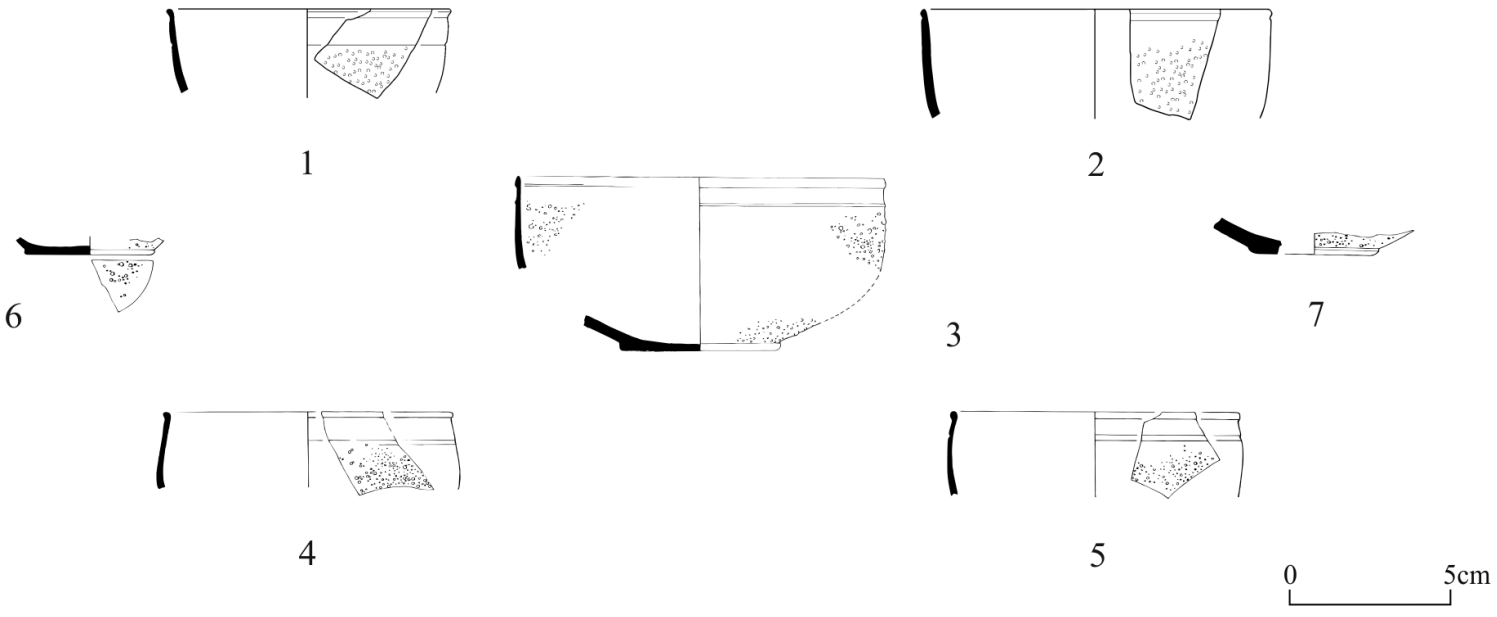

Figura 14. Cerámica de Paredes Finas de los contextos del complejo forense de Aeminium.

1977: 33-38; Remesal Rodríguez y Carreras Monfort 2003: 21 y 22).

Por último señalamos la presencia de una boca de borde almendrado y ligera curvatura hacia el interior que hemos clasificado, con ciertas reservas, dentro del tipo Haltern 71 (fig. 13, 6). Este contenedor oleario parece situarse a camino entre las antiguas Oberaden 83 y las triunfantes Dressel 20 aunque, según algunos autores, podría encuadrarse en un solo tipo junto a las primeras Tipo B de P. Berni (1998). Sea como fuera, las Haltern 71 fueron producidas en torno al cambio de Era hasta el 30/40 d.C. (González Cesteros et al. 2012). Este tipo de contenedores oleicos anteriores a la Dressel 20, como la Oberaden 83 y la Haltern 71, se documentan, sobre todo clasificadas bajo el tipo Ob. 83, en otros yacimientos portugueses como Santarém (Almeida 2006), Mesas do Castelinho, Lomba do Canho (Fabião 2000) o en la cercana ciudad de Conimbriga (Buraca 2005).

\subsection{Cerámica de paredes finas}

Los niveles estratigráficos estudiados proporcionaron varios fragmentos de cerámica de paredes finas. Sin embargo, la mayoría no pudo ser clasificada con éxito. La única forma identificada se corresponde exclusivamente con las tazas del tipo Mayet XXXVII con decoración a base de granos de arena (Mayet 1975: 73 y pl. XXXIX). Estas tacitas son de los modelos más frecuentes en la zona portuguesa, siendo los más habituales en Conimbriga (Alarcão et al. 1976: 29-30 y pl. V-VI). En este caso parecen importadas de la Bética, probablemente de la región del Guadalquivir (López Mullor 1989: 176-180), junto a otro tipo de productos como vinos, aceite y aceitunas envasados en ánforas, además de otros tipos de cerámicas comunes. Habitualmente se sugiere el segundo cuarto del siglo I d.C. como el momento álgido de la producción y comercialización de la forma en la Península (Mayet 1975: 74). En este caso, el contexto estratigráfico donde fueron recuperadas parece corroborar esta datación en época de Tiberio y Claudio.

La pasta de los fragmentos es muy fina y homogénea, de fractura rectilínea, oscilando entre el color ocre y el beige. El engobe es anaranjado, a veces amarronado, y casi siempre con reflejos metálicos. Todos los individuos presentan decoración con arena en la superficie externa que termina a $9 / 10 \mathrm{~mm}$ del borde. No obstante, una minoría presenta decoración en el exterior y en el interior, siendo este aspecto importante, ya que puede constituir un indicador cronológico en la medida en que permite una subdivisión según esquemas decorativos (López Mullor 1989: 175). En este sentido, identificamos piezas con decoración arenosa en la cara externa, salvo una franja debajo del borde - Mayet XXXVII, 1a (fig. 14, 1-2, 4-5, 7) y piezas con decoración arenosa exterior e interior, igualmente con una franja lisa debajo del borde - Mayet XXXVII, 1c (fig. 14, 3, 6). La primera variante, la más abundante en contexto peninsular, se fecha a mediados del siglo I d.C. mientras que la segunda, menos común, parece ser propia de los inicios de producción de este tipo, por el hecho de ser considerada una imitación de los originales itálicos de la forma XXXV (López Mullor 1989: 176). 


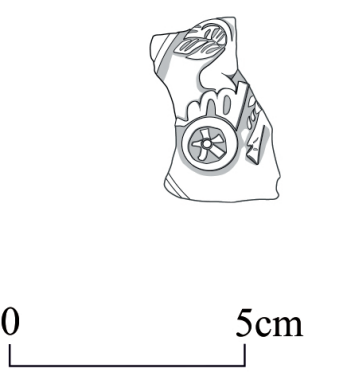

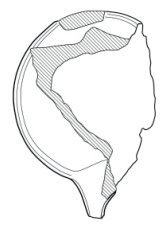

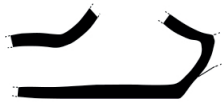

2

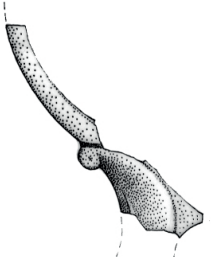

Figura 15. Lucernas de los contextos del complejo forense de Aeminium.

\subsection{Lucernas}

Los fragmentos de lucernas (discos, asas, infundibula, bases...) detectados son escasos y de pequeñas dimensiones, dificultando su clasificación tipológica. Sin embargo, estos se pueden agrupar, con base en sus características de pasta y engobe, en tres producciones distintas. La más numerosa presenta una pasta de color blanco amarillento, muy depurada y sin ningún tipo de revestimiento.

El segundo grupo se corresponde con una producción bastante cuidada, a molde, de paredes muy finas y regulares, de pasta beige amarillenta, muy depurada, con engobe de color anaranjado adherente y brillante. Asociado a esta producción contamos con dos fragmentos con volutas, un fragmento de disco que presenta decoración en alto relieve de una representación de Eros en una biga (fig. 15, 1) y otro fragmento de una piquera triangular (fig. 15, 3) que podría integrarse en el tipo IV A (=Dressel/Lamboglia 9 A-C) de las lucernas de Cartago, con una datación entre los reinados de Augusto y Claudio (Deneauve 1969: 107-121, pl. XXXV-XLI).

El último conjunto, apenas conformado por un ejemplar (fig. 15, 2), presenta una producción más grosera que las anteriores, asociada a una pasta amarronada, de matriz calcítica y compacta que debe corresponderse con una producción local o regional.

\subsection{Cerámicas comunes importadas}

\subsubsection{Cerámicas de engobe rojo pompeyano e imitaciones}

Han sido identificados cuatro fragmentos de bordes pertenecientes a platos de engobe rojo, espeso, brillante y adherente, que cubre la pared interna mientras que la externa apenas aparece revestida por una simple aguada. Este tipo de cerámicas de importación itálica, características de los períodos republicano y augusteo (Goudineau 1970; Alarcão et al. 1976: 51-58 y pl. XIIXIII), se encuentra representado en exclusiva por la forma 21 de Oberaden (fig. 16, 1).

Los otros dos individuos, de pasta más grosera y con engobes diluidos, deben considerarse imitaciones de oficinas locales o incluso tratarse de una importación a escala regional. Piezas similares fueron recuperadas en los niveles altoimperiales detectados en el exterior del foro (vid. infra).

\subsubsection{Morteros}

Por último, anótese la presencia de cinco morteros cuyas características de pasta los aproximan a las producciones béticas (Vegas 1973: 33), identificadas en numerosos yacimientos portugueses (Pinto y Morais 2007) incluida la propia Conimbriga y cuya cronología de producción abarca todo el siglo I d.C. (Alarcão et al. 1976: 71-74, 136 y pl. XVII).

Uno de los ejemplares posee paredes ligeramente arqueadas, molduradas en la cara externa y rematada por un borde engrosado y resaltado en el interior (fig. 16, 3). Los otros dos presentan el borde con engrosamiento interno y externo marcado por un resalte (fig. 16, 2, 5).

\section{LA CERÁMICA IMPORTADA DE LOS CONTEXTOS ALTOIMPERIALES DEL SECTOR OCCIDENTAL DEL FORUM DE AEMINIUM}

La renovación urbanística del barrio occidental habría sido motivada por la ampliación del foro (y del criptopórtico) a mediados del siglo I d.C., afectando sobre 


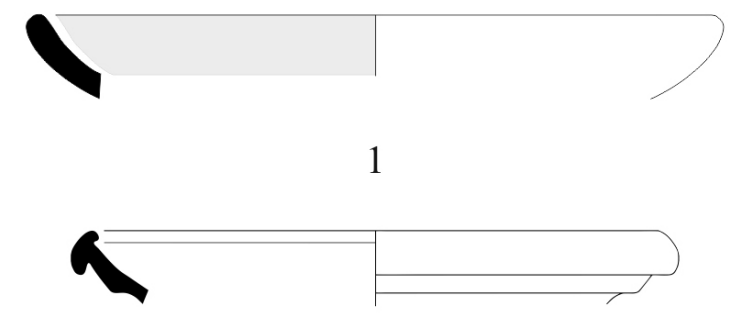

2

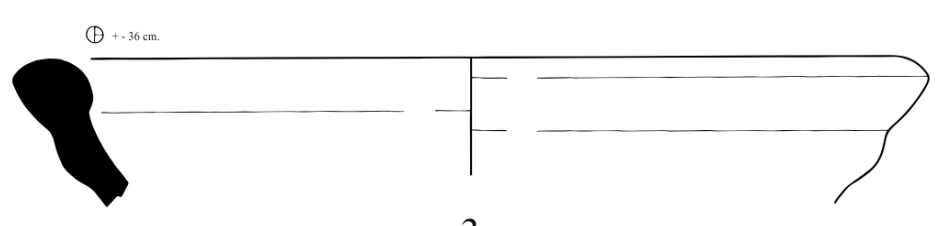

3

4
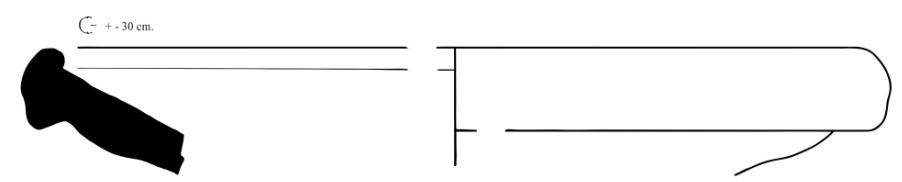

Figura 16. Cerámicas comunes importadas de los contextos del complejo forense de Aeminium.

todo a la planificación de uno de los principales ejes viarios de la ciudad -el decumanus maximus (Carvalho et al. 2010).

Es desde 1998 cuando se vienen realizando, de forma más o menos continua, excavaciones arqueológicas en el espacio anteriormente ocupado por la plaza del antiguo Palacio Episcopal (Sector B) y un pequeño sector en la confluencia de las calles Borges Carneiro y Beco das Condeixeiras (Sector A) (figs. 4 y 5). Los contextos estratigráficos más significativos identificados en estas intervenciones, y que aquí destacamos, se encuentran asociados a la construcción de la cloaca maxima que atraviesa todo esta área mostrando la orientación y el trazado del decumanus (Alarcão et al. 2009). Los niveles de aterrazamiento (con restos del proceso de construcción) que envolvían esta estructura, depositados en el momento de su construcción, aportaron un conjunto de materiales idénticos, en términos de producción y ámbito cronológico, a los exhumados en el interior del complejo forense y que permiten sugerir, de igual modo, mediados del siglo I d.C. como fecha de arranque de este proceso de obras.

El lote de terra sigillata exhumado evidencia la presencia en exclusiva de producciones itálicas y sudgálicas. A pesar de tratarse de una colección conformada, en su gran mayoría, por fragmentos informes, ha sido posible determinar alguno de los tipos. Para las itálicas, se verifica el predominio de formas fechadas entre finales de Augusto y en el reinado de Tiberio, como el plato Consp. 20 y dos copas de la forma Consp. 23 (fig. 17, 1-2).

Destaca sin embargo, por su singularidad, el fragmento de borde que, con algunas reservas, podría asignarse a un cáliz Consp. R.2.2, con borde caído y destacado de la pared (fig. 17, 3), cuya cronología se centra desde mediados a finales del reinado de $\mathrm{Au}$ gusto (Ettlinger et al. 1990: 168). También se recuperó un fondo con marca de alfarero in planta pedis en la superficie interna con la lectura [SAFEI] (fig. 17, 4). Este fragmento, cuya forma no se ha podido determinar, proviene de la oficina de Saufeius, de Arezzo, cuya producción no se prolonga más allá del reinado de $\mathrm{Au}-$ gusto. Un sello similar aparece recogido en el catálogo de Hofman (1985: Arezzo, pl. XIV, nº 274.6).

En cuanto a los servicios sudgálicos, se registra la presencia de un conjunto de formas anteriormente referenciado y conformado por tres copas Drag. 24/25, otra Drag. 27 y un plato Drag. 15/17.

En lo que concierne al material anfórico solo se han podido clasificar dos fragmentos de borde. Uno de ello parece corresponderse al tipo Dressel 1, posiblemente de la variante A (fig. 17, 5), mientras que su pasta, con 


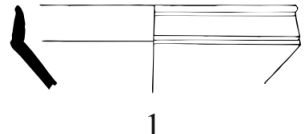

1
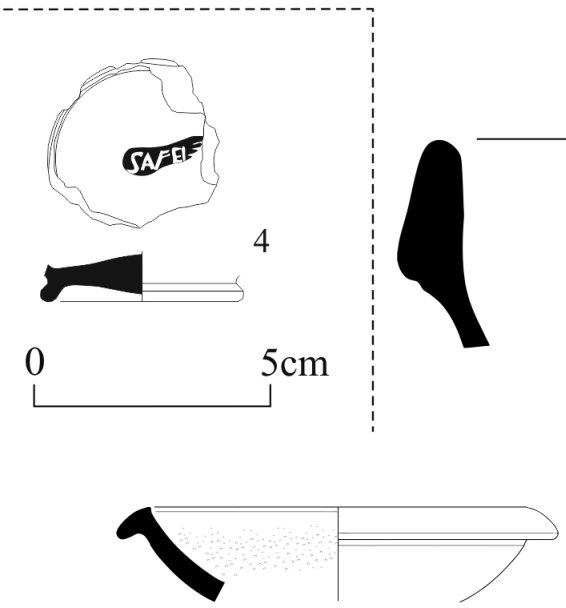

7
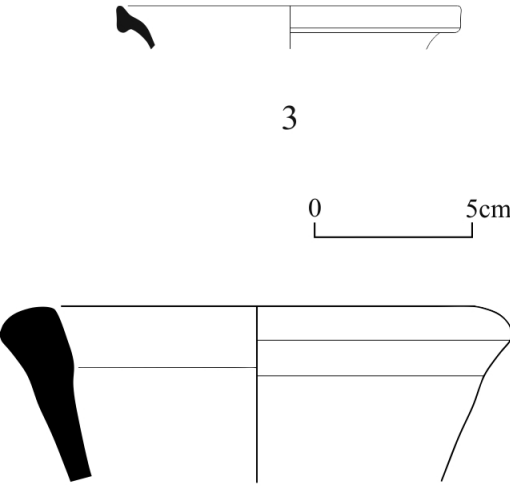

6

9

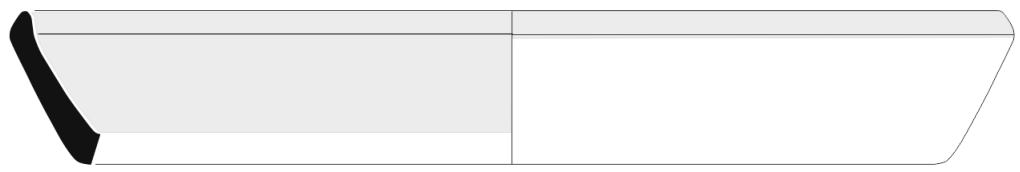

10
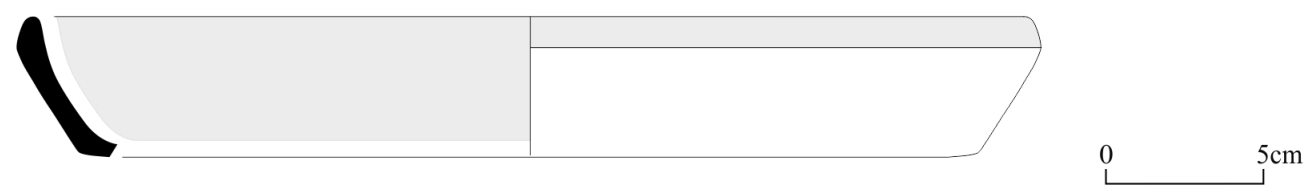

Figura 17. Cerámicas importadas de los contextos del sector occidental del fórum de Aeminium.

abundantes partículas negras volcánicas, apunta hacia una probable procedencia campana. El otro individuo se corresponde con el tipo Haltern 70 del Guadalquivir (fig. 17, 6), también documentado en los contextos del interior del foro.

También se han documentado otros tipos de piezas cerámicas de procedencia no local o regional. Además de tres fragmentos de cerámica de paredes finas y un fondo de lucerna inclasificables, se han recuperado dos morteros con superficie interna arenosa y pasta probablemente bética. El perfil de una de las piezas (fig. 17, 8) presenta similitudes con alguno de los morteros de Conimbriga ( $\mathrm{n}^{\circ}$ 54) (Alarcão et al. 1976: pl. XIX), fechado en la segunda mitad del siglo I y los inicios del siglo II d.C. aunque ese mismo perfil se fecha en Bracara Augusta en el período julio-claudio (Morais
2004: 567-568), por lo que su cronología concreta presenta hoy bastantes dudas. El otro mortero es similar al anterior en términos formales, divergiendo en el perfil del borde (fig. 17, 7). Sin embargo, se distingue en términos tecnológicos por presentar una pasta de color casi negro, a pesar del tono naranja de su superficie.

Por último, señalamos la presencia de dos platos de engobe rojo del tipo pompeyano. La pasta es compacta de tonalidad grisácea. La superficie es pulida, estando la cara interna y el exterior del borde revestidos de un engobe rojo (fig. 17, 9-10). Estos platos son una imitación de la forma 6 de Aguarod (= Oberaden 21, Luni 5). El perfil de la pared y la ligera inflexión del labio nos llevan a incluirlos en el grupo A de Conimbriga (Alarcão et al. 1976: 52; planche XII, n. ${ }^{\circ} 8$ a 11) y en el grupo I de Bracara Augusta (Delgado y Morais 2009: 
0 $5 \mathrm{~cm}$

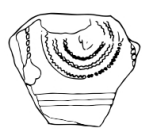

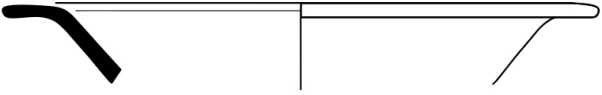
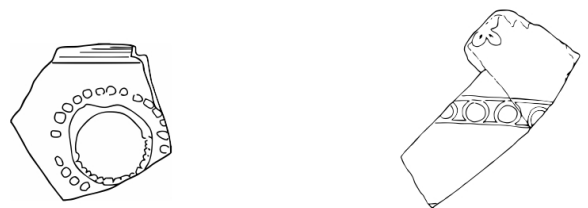

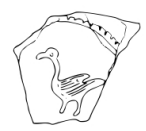

0 $5 \mathrm{~cm}$

Figura 18. Terra Sigillata Hispánica de los contextos relacionados con la fuente monumental de la fachada occidental del fórum de Aeminium.

47-49). Sus características de pasta, acabado y forma nos llevan a creer que puede tratarse de platos importados desde la ciudad de Lucus Augusti, donde son producidos y exportados desde época julio-claudia (Alcorta Irastorza 2001; Alcorta Irastorza y Bartolomé Abraira 2012). No es de extrañar la presencia temprana de esta producción en el norte de la Lusitania, ya que su presencia en Braga es cada vez más habitual y, más aún, cuando se ha identificado recientemente un ejemplar en la cercana ciudad de Conimbriga.

Los contextos estratigráficos hasta ahora analizados y asociados a la reformulación urbanística en el entorno del complejo forense arrojan un horizonte cronológico estrechamente relacionado con el proceso de ampliación del forum, con abundantes materiales datantes que continúan apuntando hacia una cronología pre-flavia para el inicio del extenso programa arquitectónico. En relación con esto, sin embargo, no podemos obviar mencionar la aparición de un conjunto de materiales disonantes de la realidad hasta el momento constatada, en los niveles que asociamos a la construcción de la gran fuente monumental localizada en la fachada occidental del criptopórtico (Alarcão et al. 2009; Carvalho et al. 2010) (figs. 4 y 5). De hecho, además de TSI (11 fragmentos) y dos platos sudgálicos (Drag. 18, 18/31) se identificó un lote compuesto por 97 pequeños fragmentos de terra sigillata hispánica. Estas piezas destacan por su excelente acabado, con un barniz rojo vivo y brillante, similar al designado como "grupo B" de la TSH de Conimbriga (Delgado et al. 1975: 155), pudiendo representar las primeras remesas de las producciones hispánicas llegadas a Aeminium. Además de los fragmentos de piezas decoradas (Drag. 29?, 29/37?, 37?), apenas ha sido posible clasificar un plato de la forma Drag. 15/17 y otro de la forma Hisp. 46 (fig. 18, 1).
Queda así planteada la cuestión de si los niveles estratigráficos donde estas piezas fueron recogidos, que inicialmente fueron atribuidos al proceso de ampliación del criptopórtico (y de remodelación del decumanus), no estarán realmente relacionados con intervenciones o arreglos puntuales realizados en el local o son testimonio del final del proceso de obras en este sector, acontecido, probablemente, más de una década después de su inicio.

\section{CONSIDERACIONES FINALES}

El extenso programa de intervenciones arqueológicas (entre 1992 y 2008) que antecedieron y complementaron el proceso de remodelación y ampliación del Museo Nacional de Machado de Castro en Coímbra, permitió recuperar un conjunto de datos que, desde el punto de vista del repertorio de materiales exhumado (en concreto de la cerámica importada que aquí se analiza), define las secuencias cronológicas referentes a las ocupaciones de este espacio. Conviene subrayar, sin embargo, que el ámbito cronológico propuesto a partir del estudio de estos materiales se asienta, en primer lugar, en su contextualización estratigráfica. De hecho, no se podrá disociar el estudio de esta colección de su contexto exacto de proveniencia en la excavación. Todos los fragmentos analizados fueron recuperados en una estratigrafía sellada, de lectura clara y precisa, asociados a la reconstrucción del forum. Al mismo tiempo, se presentan los contextos asociados a la gran ampliación del complejo forense de Aeminium y los contextos de los niveles de construcción relacionados con la remodelación urbanística del barrio occidental (poniente) contiguo al foro, estructurado en función del decumanus maximus, bajo el cual circula la cloaca maxima de la ciudad. 
La secuencia estratigráfica registrada en el interior del complejo forense constituye esencialmente una serie de estratos conformados por tierra con el objetivo de alterar, nivelar y rellenar espacios en el momento de su construcción, apenas alterados en su parte superior por la presencia de algunas fosas con detritos medievales. La cronología del depósito o formación de estos niveles romanos coincide necesariamente con la cronología de construcción de diversas estructuras asociadas a la ampliación de foro, en concreto de los voluminosos muros del criptopórtico.

De un modo general, la presencia en exclusiva de sigillata itálica y gálica, asociada con el resto de materiales importados datantes, se fecha genéricamente en la primera mitad del siglo I, lo que nos lleva a fijar el momento de la gran ampliación de esta obra de arquitectura de la Lusitania romana a mediados de la primera centuria, posiblemente durante el reinado de Claudio.

El repertorio formal de las producciones itálicas está conformado esencialmente por productos fechados desde finales del período augusteo y el reinado de Tiberio. Por otro lado, las producciones gálicas presentan modelos del período pre-flavio (imitando esencialmente prototipos itálicos), particularmente típicos de la época de Tiberio/ Claudio/Nerón, siendo en su mayoría encuadrables en la fase de "esplendor" de la producción de La Graufesenque, establecida por Hermet entre las décadas del 40 al 60. La ausencia de formas de los llamados "servicios flavios" constituye un factor que, unido a la importante presencia de TSI y la total ausencia de TSH, contribuye a delimitar el arco cronológico de este conjunto de materiales. El material anfórico, por su parte, a pesar de ser escaso asume cierta importancia no solo por mostrar la presencia de ciertos productos en la ciudad sino también por encuadrarse perfectamente en este lapso temporal.

De igual modo, el conjunto de cerámica importada identificada en los contextos analizados del barrio urbano situado a poniente revela el mismo tipo de producciones y cronologías. El proceso de obras del espacio exterior contiguo al foro, en concreto la construcción de la cloaca maxima o el nuevo trazado del decumanus maximus (y la construcción de la gran fuente adosada a su fachada occidental), se produjo de manera simultánea o en un momento inmediatamente posterior a su ampliación y, siendo así, todavía a mediados del siglo I d.C. en un período seguramente pre-flavio.

\section{Agradecimientos}

Los autores quieren agradecer a José Luís Madeira y a Sara Almeida la realización de los dibujos cerámicos, y a Danilo Pavone, como autor de las fotografías de la figura 2.

Parte de esta investigación se enmarca dentro del proyecto de la Universidad de Vigo "Fellowsea" (International Fellowship Program) dentro de acciones Marie Curie del Seventh Framework Programme de la U.E.

\section{BIBLIOGRAFÍA}

Aguarod Otal, C. (1991): Cerámica romana importada de cocina en la Tarraconense. Zaragoza, Institución "Fernando el Católico".

Alarcão, A. M. (1971): “A «Terra Sigillata» Itálica em Portugal”, en Actas do II Congresso Nacional de Arqueologia vol. II: 421-431. Coimbra (1970). Coimbra, Junta Nacional de Educação.

Alarcão, J. (2008): Coimbra: a montagem do cenário urbano. Coimbra, Imprensa da Universidade de Coimbra.

Alarcão, J.; Delgado, M.; Mayet, F.; Alarcão, A. y Ponte, S. (1976): Fouilles de Conimbriga VI. Céramiques Diverses et Verres. Paris, Diffusion E. de Bocard.

Alarcão, J.; André, P.; Barrelas, P.; Carvalho, P.; Santos, F. y Silva, R. C. (2009): The Forum of Aeminium: The search for the original design. Lisboa, IMC, MNMC and EDIFER.

Alcorta Irastorza, E. (2001): Lucus Augusti II. Cerámica común romana de cocina y mesa hallada en las excavaciones de la ciudad. La Coruña, Fundación Barrié de La Maza.

Alcorta Irastorza, E. y Bartolomé Abraira, R. (2012): "Muestras de cerámica engobada romana de producción local de Lucus Augusti”, en D. Bernal y A. Ribera i Lacomba (eds.), Cerámicas hispanorromanas II: 699-724. Cádiz (2012). Cádiz, servicio de publicaciones de la Universidad de Cádiz.

Almeida, R. (2006): As produções anfóricas do Guadalquivir no quadro das importações de Scallabis: contributo para o conhecimento dos tipos minoritários no Ocidente Peninsular. Tesis Maestría, Faculdade de Letras da Universidade de Lisboa. Inédita.

Almeida, S.; Silva, R. C. y Vilaça, R. (2015): "Pre-roman testimonies in the Aeminium forum (Coimbra, Portugal)". Antrope 3: 39-63.

Bémont, C. (1976): Recherches méthodologiques sur la céramique sigillée: les vases estampillés de Glanum. Rome, Bibliothéque des Écoles Françaises d'Áthénes et Rome. 
Benoit, F. (1957): “Typologie et épigraphie amphoriques: les marques de SESTIUS". Rivista di Studi Liguri 23: 247-285.

Berni Millet, P. (1998): Las ánforas de aceite de la Bética y su presencia en la Cataluña romana. Col·lecció Instrumenta, vol. 4. Barcelona, Publicacions i Edicions UB.

Bonet Rosado, H. y Mata Parreño C. (1988): "Imitaciones de cerâmica campaniense en la Edetania y Contestania". Archivo Español de Arqueologia 61 (157158): 1-39.

Bourgeois, A. y Mayet, F. (1991): Les sigillées. Fouilles de Belo VI. Paris, Publ. de la Casa de Velázquez 14.

Buraca, I. (2005): Civitas Conímbriga: Anforas romanas. Tesis Maestría, Faculdade de Letras da Universidade de Coimbra. Inédita.

Carvalho, P. C. (1998): O Forum de Aeminium. Lisboa, Instituto Português de Museus.

Carvalho, P. C.; Matias, D.; Ramos, A.; Ribeiro, C.; Santos, F. y Silva, R. C. (2010): "Caminhando em redor do forum de Aeminium (Coimbra, Portugal)", en T. Nogales Basarrate (ed.), Ciudad y Foro en Lusitania Romana. Studia Lusitana 4: 69-88. Mérida, Museo Nacional de Arte Romano.

Carvalho, P. C. (2013): “A arqueologia na obra do MNMC: para uma visão integrada do lugar”. Revista Património 1: 114-119.

Colls, D.; Étienne, R.; Lequément, R.; Liou, B. y Mayet, F. (1977): L'épave Port-Vendres II et le commerce de la Bétique à l'èpoque de Claude. Archaeonautica 1. Paris, Éditions du Centre National de la Recherche Scientifique.

Delgado, M. (1971): "Cerâmica campaniense em Portugal", en Actas do II Congresso Nacional de Arqueologia vol. II: 403-420. Coimbra (1970). Coimbra, Junta Nacional de Educação.

Delgado, M.; Mayet, F. y Alarcão, A. (1975): Fouilles de Conimbriga, IV (Les Sigilées). Paris, E. de Boccard.

Delgado, M. y Morais, R. (2009): Guia das cerâmicas de produção local de Bracara Augusta. Porto, CITCEM.

Deneauve, J. (1969): Lampes de Carthage. Paris, Editions du Centre de la Recherche Scientifique.

Desbat, A. (1998): "L'arrêt des importations de Dressel 1 en Gaule", en Actes du congrès d'Istres, 21-24 mai 1998: 31-35. Marseille, Société Française d’Étude de la Céramique Antique en Gaule (SFECAG).

Diogo, A. M. D. (1980): Marcas de "Terra Sigillata» Itálica em Portugal. Lisboa, Grupo de Estudos de Cultura Antiga.
Ettlinger, E. et al. (1990), Conspectus Formarum Terrae Sigigillatae Italico Modo Confectae. Materialen zur romisch-germanischen Keramik 10. Bonn, Dr. Rudolf Habelt Gmbh.

Fabião, C. (1989): Sobre as ânforas do acampamento romano da Lomba do Canho (Arganil). Lisboa, UNIARQ / INIC.

Fabião, C. (2000): "Sobre as mais antigas ânforas «romanas» da Baetica no ocidente peninsular", en Actas Congreso Internacional Ex Baetica Amphorae. Conservas y vino de la Bética en el Imperio Romano (2.): 665-682. (Écija y Sevilla, 17 al 20 de diciembre de 1998), Écija, Gráficas Sol.

Fiches, J. L. (1977): "Formes rares en sigilée ornée de la Gaule du sud trouvées en Languedoc-Roussillon". Figlina 2: 127-143.

Fiches, J. L. (1978): "Les coupes Drag. 29 en Languedoc-Roussillon”. Figlina 3: 43-70.

García Vargas, E.; Almeida, R. R. y González Cesteros, H. (2011): "Los tipos anfóricos del Guadalquivir en el marco de los envases hispanos del siglo I a.C. Un universo heterogéneo entre la imitación y la estandarización". Spal 20: 185-283.

García Vargas, E.; Almeida, R. R. y González Cesteros, H. (2013): “Ovoide 4 (Valle del Guadalquivir)", en Amphorae ex Hispania. Paisajes de producción $y$ de consumo http://amphorae.icac.cat/ tipol/view/68 (17 de junio de 2013).

Genin, M. (ed.) (2007): La Graufesenque (Millau, Aveyron). II. Sigillées et autres productions. Études d'Archéologie urbaine Pessac, Éditions de la Fédération Aquitania.

González Cesteros, H.; García Vargas, E. y Almeida, R. R. (2012): "Haltern 71 (Valle del Guadalquivir)", en Amphorae ex Hispania. Paisajes de producción y de consumo http://amphorae.icac.cat/tipol/view/5 (07 de Agosto de 2012).

González Cesteros, H.; Almeida, R. R. y García Vargas, E. (2013): "Ovoide 1 (Valle del Guadalquivir)", en Amphorae ex Hispania. Paisajes de producción y de consumo http://amphorae.icac.cat/tipol/view/21 (17 de junio de 2013).

Goudineau, C. (1968): La céramique aretine lisse: fouilles de l'École Française de Rome à Bolsena (Poggio Moscini) 1962-1967. École Française de Rome, Sup. 6: IV. Paris, Diffusion E. de Boccard.

Goudineau, C. (1970): "Note sur la céramique à engobe interne rouge pompéien". Mélanges d'archéologie e d'histoire 82 (1): 159-186.

Hartley, B. R. y Dickinson, B. M. (2008): Names on Terra Sigillata. An Index of Makers' Stamps \& 
Signatures on Gallo-Roman Terra Sigillata (Samian Ware). Vol. 3. London, Institute of Classical Studies University of London.

Hofmann, B. (1985): Catalogue des estampilles sur vaisselle sigillée. Revue Archéologique Sites 27. Gonfaron, Association Française d'Archéologie Métropolitaine.

Kenrick, P. M. (1997): “Cn. Ateius - the inside history”. Rei Cretariae Romane Fautorum Acta 35: 179-190.

López Mullor, A. (1989): Las cerámicas romanas de paredes finas en Cataluña. Quaderns Científics i Técnics, 2. Barcelona, Diputació de Barcelona, Servei del Patrimoni Arquitectònic Local.

Luís, L. (2010): “Cerâmica Campaniense", en J. Alarcão; P. Carvalho y A. Gonçalves (coord.), Castelo da Lousa - Intervenções Arqueológicas de 1997 a 2002. Studia Lusitana V: 111-138. Mérida, Museo Nacional de Arte Romano.

Lutz, M. (1974): "La céramique sigillée en Gaule". Les Dossiers de l'Archéologie 6: 20-42.

Mantas, V. (1992): "Notas sobre a estrutura urbana de Aeminium”. Biblos 68: 487-513.

Martin, T. y Garnier, J. F. (1977): “Céramique arétine et sigillée sud-gauloise precoce d'Excisum à Villeneuve-Sur-Lot". Figlina 2: 145-188.

Mayet, F. (1975): Les céramiques à paróis fines dans la Péninsule Ibérique. Paris, Publications du Centre Pierre Paris 1.

Molina Vidal, J. (2000): "Las primeras exportaciones béticas en el Mediterráneo Occidental", en $A c$ tas Congreso Internacional Ex Baetica Amphorae. Conservas y vino de la Bética en el Imperio Romano (2): 637-645. (Écija y Sevilla, 17 al 20 de diciembre de 1998), Écija, Gráficas Sol.

Morais, R. (2004): “Os almofarizes béticos em Bracara Augusta”, en D. Bernal; L. Lagóstena (eds.), Figlinae Baeticae. Talleres alfareros y producciones cerámicas en la Bética romana II. BAR Internacional Series 1266: 567-570. Oxford, Archaeopress.

Morais, R. (2005): Autarcia e Comércio em Bracara Augusta. Contributo para o estudo económico da cidade no período Alto-Imperial. Bracara Augusta, Escavações Arqueológicas 2. Braga, UAUM/Narq.

Morel, J.-P. (1981): Céramique campanienne. Les Formes. Roma, École Française de Rome.

Oxé, A. y Comfort, H. (1968): Corpus Vasorum Arretinorum. A Catalogue of the signaturas, Shapes and Chronology of Italian Sigillata, Bonn, Rudolf Habelt.

Oxé, A.; Comfort, H. y Kenrick, P. (2000): Corpus Vasorum Arretinorum. A Catalogue of the signaturas, Shapes and Chronology of Italian Sigillata, Bonn, Rudolf Habelt.
Oleiro, J. M. B. y Alarcão, J. (1973): "Le Cryptoportique d'Aeminium (Portugal)". Les cryptoportiques dans l'architecture romaine. Collection de l'École Française de Rome 14: 349-367. Roma, CNRS.

Oswald, F. (1983): Index des Estampilles sur Sigillée. Revue Archéologique Sites 21. Avignon, Association Française d'Archéologie Métropolitaine.

Oswald, F. y Pryce, T. D. (1966): An Introduction to the Study of Terra Sigillata. London, Gregg Press LTD.

Pinto, I. y Morais, R. (2007): "Complemento de comércio das ânforas: a cerâmica comum bética no territorio portugués", en L. Lagóstena, D. Bernal, A. Arévalo (eds.), Cetariae 2005. BAR Internacional Series 1266: 235-254. Oxford, Archaeopress.

Polak, M. (2000): South Gaulish Terra Sigillata with Potters'Stamps from Vechten. Rei Cretariae Romanae Fautorum Acta (Supplementum 9). Nijmegen, Katholieke Universiteit Nijmegen.

Remesal Rodríguez, J. y Carreras Monfort, C. (2003): "Historia de la recerca", en Culip VIII i les àmfores Haltern 70: 19-23. Girona, Museu d'Arqueologia de Catalunya.

Silva, R. C. (2011): "O quarteirão urbano a poente do forum de Aeminium (Coimbra, Portugal): a sua configuração ao longo do séc. I d. C. '. Conimbriga 50: 79-99.

Silva, R. C.; Fernández Fernández, A. y Carvalho, P. (2015): "Contextos e cerâmicas tardo-antigas do fórum de Aeminium (Coimbra)". Revista Portuguesa de Arqueologia 18: 237-256.

Silva, R. B. (2005): As “marcas de oleiro" em terra sigillata da Praça da Figueira: uma contribuição para o conhecimento da economia de Olisipo (séc. I a.C.-séc. II d.C.). Tesis Maestría, Universidade do Minho. Inédita.

Vernhet, A. (1979): La Graufesenque, atelier de potier gallo-romain. Toulouse, Musée Saint Raymond de Toulouse, Musée Municipal de Millau.

Vernhet, A. (1986): "Centre de production de Millau: atelier de La Graufesenque". Documents d'Archéologie Française (la terre sigillée gallo-romaine. Lieux de production du Haut Empire: implantations, produits, relations) 6: 96-103. Paris, Maison des Sciences de l'Homme.

Viegas, C. (2003): A terra sigillata da Alcáçova de Santarém: cerâmica, economia e comércio. Trabalhos de Arqueologia 26. Lisboa, Instituto Português de Arqueologia.

Zevi, F. (1966): "Apunti sulle anfore romane I. La tavola tipologica de Dressel”. Archaeologia Classica 18: 208-247. 